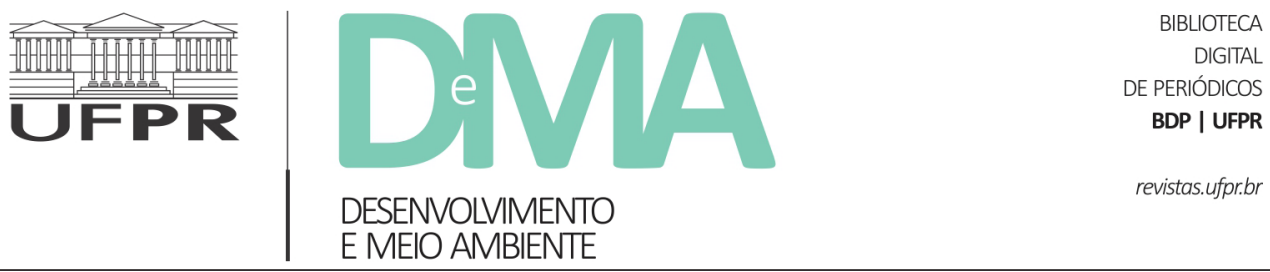

\title{
Licuri (Syagrus coronata): características, importâncias, potenciais e perspectivas do pequeno coco do Brasil
}

\section{Licuri (Syagrus coronata): characteristics, importance, potential and perspectives of the small coconut from Brazil}

\author{
Julian dos Santos GUIMARÃES ${ }^{*}$, Ricardo Kenji SHIOSAKI ${ }^{1}$, Marianne Louise Marinho MENDES ${ }^{1}$ \\ ${ }^{1}$ Universidade de Pernambuco (UPE), Petrolina, PE, Brasil. \\ *E-mail de contato: julian-guimaraes@hotmail.com
}

Artigo recebido em 30 de agosto de 2019, versão final aceita em 15 de dezembro de 2020, publicado em 20 de setembro de 2021.

RESUMO: Conhecida como a "árvore salvadora da vida", o licuri (Syagrus coronata (Martius) Beccari) é uma das principais palmeiras nativas do Semiárido brasileiro, desenvolvendo um importante papel socioeconômico, cultural e ambiental para a subsistência do sertanejo. Porém, apesar de sua importância, observa-se que os licurizais encontram-se sob ameaça devido ao desmatamento, queimadas e exploração de forma extrativista. Por conta disso, o objetivo do presente estudo foi realizar uma revisão e análise bibliográfica sobre o licuri, destacando sua importância, potenciais, perspectivas futuras e a necessidade de sua preservação e conservação. Para esse fim, recorreu-se às bases de dados Periódico CAPES, SciELO, BDTD e BVS, através dos descritores "Licuri", "Syagrus coronata" e "Syagrus coronata (Martius) Beccari", abrangendo a seleção de artigos, manuais, teses e dissertações. Por ser uma planta nativa do Brasil, este trabalho encontra-se cadastrado no Sistema Nacional de Gestão do Patrimônio Genético e do Conhecimento Tradicional Associado (SisGen), sob o $\mathrm{n}^{\circ} \mathrm{AD} 6 \mathrm{~A} 6 \mathrm{AB}$, atendendo ao previsto em lei e seus regulamentos. A revisão segue estruturada em seções, além da introdução. Na primeira, faz-se uma breve apresentação do licuri sobre suas características gerais e distribuição geográfica. Na segunda, aborda-se a sua importância socioeconômica e cultural, posicionando sua utilização e reconhecimento pela população semiárida. $\mathrm{Na}$ terceira, destaca-se a sua indispensável importância ecológica e ambiental, considerada uma "espéciechave" do bioma Caatinga. Em seguida, como parte fundamental da dieta cotidiana local, apresenta-se seu potencial alimentício e nutricional, expondo principalmente suas utilizações culinárias e sua composição nutricional. Por fim, demonstram-se as perspectivas acerca de seus estudos e espera-se contribuir fornecendo subsídios científicos que ampliem a interiorização da pesquisa, a capacitação e a disseminação de informações acerca do licuri.

Palavras-chaves: Ouricuri; Arecaceae; Oleaginosa; Semiárido.

Desenvolv. e Meio Ambiente usa uma Licença Creative Commons - Atribuição-NãoComercial-SemDerivações 4.0 Internacional 
ABSTRACT: Known as the "life-saving tree", the licuri (Syagrus coronata (Martius) Beccari), is one of the main native palm trees in the Brazilian Semiarid region, developing an important socio-economic, cultural and environmental role for the sertanejo's subsistence. However, despite its importance, it is observed that licurizais are under threat due to deforestation, fires, and extractive exploitation. Because of this, the objective of the present study was to carry out a review and bibliographic analysis of licuri, highlighting its importance, potentials, future perspectives, and the need for its preservation and conservation. For this purpose, the CAPES, SciELO, BDTD, and BVS databases were used, using the descriptors "Licuri", "Syagrus coronata" and "Syagrus coronata (Martius) Beccari", covering the selection of articles, manuals, theses, and dissertations. As it is a plant native to Brazil, this work is registered in the National System for the Management of Genetic Heritage and Associated Traditional Knowledge (SisGen), under $\mathrm{n}^{\circ} \mathrm{AD} 6 \mathrm{~A} 6 \mathrm{AB}$, in compliance with the law and its regulations. The review remains structured in sections, in addition to the introduction. In the first, there is a brief presentation of the licuri on its general characteristics and geographical distribution. In the second, it addresses its socioeconomic and cultural importance, positioning its use and recognition by the semi-arid population. In the third, it highlights its indispensable ecological and environmental importance, considered a "key species" of the Caatinga biome. Then, as a fundamental part of the local daily diet, it presents its food and nutritional potential, exposing mainly its culinary uses and its nutritional composition. Finally, the perspectives on their studies are demonstrated and it is hoped to contribute by providing scientific subsidies that expand the internalization of research, training, and the dissemination of information about licuri.

Keywords: Ouricuri; Arecaceae; Oilseed; Semiarid.

\section{Introdução}

O licuri, de nome científico Syagrus coronata (Martius) Beccari, é uma das principais palmeiras nativas do Semiárido brasileiro, predominando nas regiões secas e áridas do bioma Caatinga e encontra-se entre suas principais espécies exploradas (Beltrão \& Oliveira, 2007; Drumond, 2007; Carvalho et al., 2014; Maia et al., 2017). Conhecida como a "árvore salvadora da vida", por ser uma palmeira totalmente aproveitável, desenvolve um importante papel socioeconômico, cultural e ambiental para a subsistência do sertanejo (Rocha et al., 2009; Miranda \& Silva, 2011; Aroucha \& Aroucha, 2013).

Esta palmeira é utilizada na alimentação humana, fazendo parte da dieta cotidiana local, como registrado no Tratado Descritivo do Brasil publicado em 1587 pelo colono português Gabriel Soares de Sousa (Santana et al., 2011; Slow Food, 2015). Além disso, a amêndoa do licuri também serve de alimento para inúmeros animais silvestres como, por exemplo, a arara-azul-de-lear (Anodorhynchus leari), que se encontra em risco de extinção (Lima et al., 2014; Slow Food, 2015).

Porém, apesar de sua importância, observa-se que os licurizais encontram-se sob ameaça devido ao desmatamento, queimadas e exploração de forma extrativista, levando a uma rápida diminuição dessa espécie vegetal (Aroucha \& Aroucha, 2013; Slow Food, 2015).

Os licurizais florescem e frutificam por um longo período do ano e após sofrerem maturação completa, os frutos desprendem-se do cacho e caem no chão, onde podem ser contaminados por microrganismos, com deterioração e alteração em praticamente todas as partes do fruto, podendo comprometer a sua qualidade alimentar, sensorial e nutricional (Aroucha \& Aroucha, 2013; Jesus \& Santos, 2017). Além disso, pouco se conhece sobre a conservação pós-colheita do licuri (Jesus \& Santos, 2017). 
Sabe-se que as amêndoas apresentam propriedades organolépticas descritas como remarcáveis, sendo consumidas torradas, cozidas, verdes ou frescas, além de serem definidas como saborosas, nutritivas e muito ricas em óleo (Carvalho et al., 2014; Slow Food, 2015).

De acordo com Crepaldi et al. (2001), a composição nutricional das amêndoas indica que estas são altamente calóricas e constituídas principalmente de lipídios $(49,20 \%)$ e proteínas (11,50\%). Por sua vez, Santana et al. (2011), ao também analisarem as amêndoas do licuri, encontraram valores semelhantes para lipídios (50,55\%), contudo divergiram do teor de proteínas $(2,90 \%)$ avaliado. Já Silva et al. (2012), apresentaram os valores mais discrepantes, sendo o total de lipídios mais baixos $(30,04 \%)$ e o total de proteínas mais elevado (20,64\%.). Por conta disso, Santana et al. (2011) concluíram ser necessário mais pesquisas que ampliem o conhecimento acerca da composição nutricional do licuri, visto que ele apresenta ainda um grande potencial a ser explorado.

Devido a essas características nutricionais, o licuri contribui de forma importante para a segurança alimentar das populações sertanejas, tratando-se de uma matéria-prima utilizada para combater a fome no Nordeste e em pesquisas para a produção de gêneros alimentícios (Miranda \& Silva, 2011; Aroucha \& Aroucha, 2013). Estudos que testaram o licuri no preparo de barras de cereais ou biscoitos indicaram a aceitação dos produtos, aconselhando o uso do licuri como ingrediente para o preparo destes tipos de produtos, motivando pesquisas de desenvolvimento de produtos à base de amêndoas do licuri (Folegatti et al., 2006; Santos et al., 2014a).

Portanto, diante do seu caráter estratégico e devido à escassez de estudos, faz-se clara a necessi- dade de pesquisas que envolvam as potencialidades do licuri (Santana et al., 2011; Aroucha \& Aroucha, 2013), sendo de fundamental importância para fornecer subsídios científicos, que contribuirão para otimizar a sua utilização, agregar valor, fortalecer sua preservação e promover o desenvolvimento sustentável do Semiárido brasileiro (Carvalho et al., 2014; Slow Food, 2015).

Por conta disso, o objetivo do presente estudo foi realizar uma revisão e análise bibliográfica sobre o licuri, destacando sua importância, potenciais, perspectivas futuras e a necessidade de sua preservação e conservação

\section{Metodologia}

O presente estudo é pautado em revisão de literatura. Para esse fim, recorreu-se às bases de dados Periódico CAPES, SciELO, BDTD e BVS, por congregarem periódicos internacionais e nacionais. Optou-se por não utilizar parâmetros de exclusão temáticos ou cronológicos, afim de reunir uma maior quantidade de referências bibliográficas e documentais. O levantamento foi realizado no período entre 06/02/2019 e 11/03/2019, através dos descritores "Licuri", "Syagrus coronata" e "Syagrus coronata (Martius) Beccari", abrangendo publicações nacionais e estrangeiras.

Visto que o licuri é uma planta nativa do Brasil, este trabalho adequa-se a Lei $\mathrm{n}^{\circ} 13.123$, de 20 de maio de 2015, que dispõe sobre o acesso ao patrimônio genético, proteção e acesso ao conhecimento tradicional associado e sobre a repartição de benefícios para conservação e uso sustentável da biodiversidade. Portanto, este trabalho encontra-se cadastrado no Sistema Nacional de Gestão do Pa- 
trimônio Genético e do Conhecimento Tradicional Associado (SisGen), sob o ${ }^{\circ}$ AD6A6AB, atendendo ao previsto em lei e seus regulamentos.

A revisão segue estruturada em seções, além da introdução. Na primeira, faz-se uma breve apresentação do licuri sobre suas características gerais e distribuição geográfica. Na segunda, aborda-se a sua importância socioeconômica e cultural, posicionando sua utilização e reconhecimento pela população semiárida. $\mathrm{Na}$ terceira, destaca-se seu valor ecológico e ambiental, sendo o licuri uma "espécie-chave" do bioma Caatinga. Em seguida, como parte fundamental da dieta cotidiana local, apresenta-se seu potencial alimentício e nutricional, expondo principalmente suas utilizações culinárias e sua composição nutricional. Por fim, demonstra-se as perspectivas de uso acerca de seus estudos e conclui-se com as considerações finais.

\section{Licuri (Syagrus coronata (Martius) Beccari)}

\subsection{Características gerais e distribuição geográficas}

As palmeiras (Arecaceae) existem em todos os continentes há mais de 130 milhões de anos. $\mathrm{O}$ Brasil, por exemplo, já foi chamado de Pindorama, uma designação indígena tupi-guarani da era colonial, que significa "terra, lugar ou região de palmeiras" (Bondar, 1964; Carvalho et al., 2014). Encontra-se entre essa grande diversidade de palmeiras, o licurizeiro (Syagrus coronata (Martius) Beccari), nome este que faz referência as suas folhas arrumadas em forma de coroa (Figura 1) (Aroucha \& Aroucha, 2013).

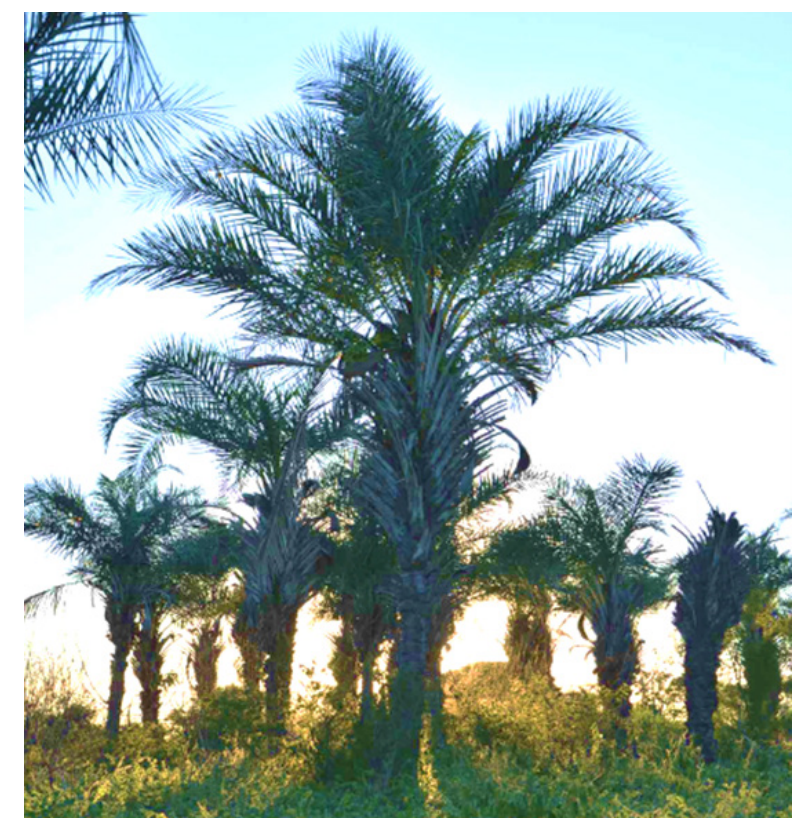

FIGURA 1 - Licurizeiro (Syagrus coronata (Martius) Beccari). FONTE: Slow Food (2015).

Embora exista uma grande divergência acerca do quantitativo de representantes de Arecaceae, acredita-se que existam por volta de duas mil espécies, reunidas em cerca de 200 gêneros (Beltrão \& Oliveira, 2007; Rocha et al., 2009). Relata-se que no Brasil ocorram 43 gêneros e cerca de 200 espécies. Só na região Nordeste são referidas 70 espécies, distribuídas em 16 gêneros, sendo que Syagrus apresenta a maior representatividade, correspondendo 16 espécies (Beltrão \& Oliveira, 2007; Rocha et al., 2009).

Essa cultura foi batizada com diferentes nomes por povos e comunidades tradicionais, agroextrativistas e agricultores familiares. São relatados pelo menos 36 nomes populares: adicuri, alicuri, aracui, aracuri, aribury, aricui, aricuí, aricuri, ariri, aruuri, 
butiá, butua, cabeçudo, coco-cabeçudo, coqueiro-aracuri, coqueiro-cabeçudo, coqueiro-dicori, coqueiro-dicuri, dicori, dicuri, iricuri, licuri, licurizeiro, nicori, nicori-iba, nicuri, nicury, ouricuri, ouricurizeiro, uricuri, uricuriba, uricurti, uriricuri, urucuri, urucuriiba e ururucuri (Aroucha \& Aroucha, 2013; Carvalho et al., 2014; Jesus \& Santos, 2017).

Além disso, é uma das principais palmeiras nativas, ocorrendo principalmente nas Zonas Subúmida seca e Semiárida, sendo comum no bioma Caatinga mas apresenta-se também em algumas áreas do Cerrado, em algumas localidades das restingas e dos tabuleiros do bioma Mata Atlântica e com presença nas serras e nos vales de áreas de transição entre estes três biomas (Beltrão \& Oliveira, 2007; Rocha et al., 2009; Aroucha \& Aroucha, 2013).
Predomina, portanto, ao leste do Rio São Francisco, nos Estados de Alagoas, Bahia, Sergipe e Pernambuco e norte de Minas Gerais (Figura 2) (Drumond, 2007; Oliveira et al., 2013; Carvalho et al., 2014).

O licurizeiro pode sobreviver em terras secas e de solos muito drenados de areias, cascalhos, pedregulhos e pedras, necessitando de pouca umidade para viver, conseguindo suportar até secas prolongadas (Beltrão \& Oliveira, 2007; Carvalho et al., 2014). Contudo, mesmo que aparentemente seja o contrário, o licuri prefere solos de melhor qualidade e mais férteis (Aroucha \& Aroucha, 2013).

Os licurizeiros apresentam uma altura mediana, podendo atingir entre 8 a $11 \mathrm{~m}$, com caule ou estipe de 20 a $40 \mathrm{~cm}$ de diâmetro, em forma de tubo

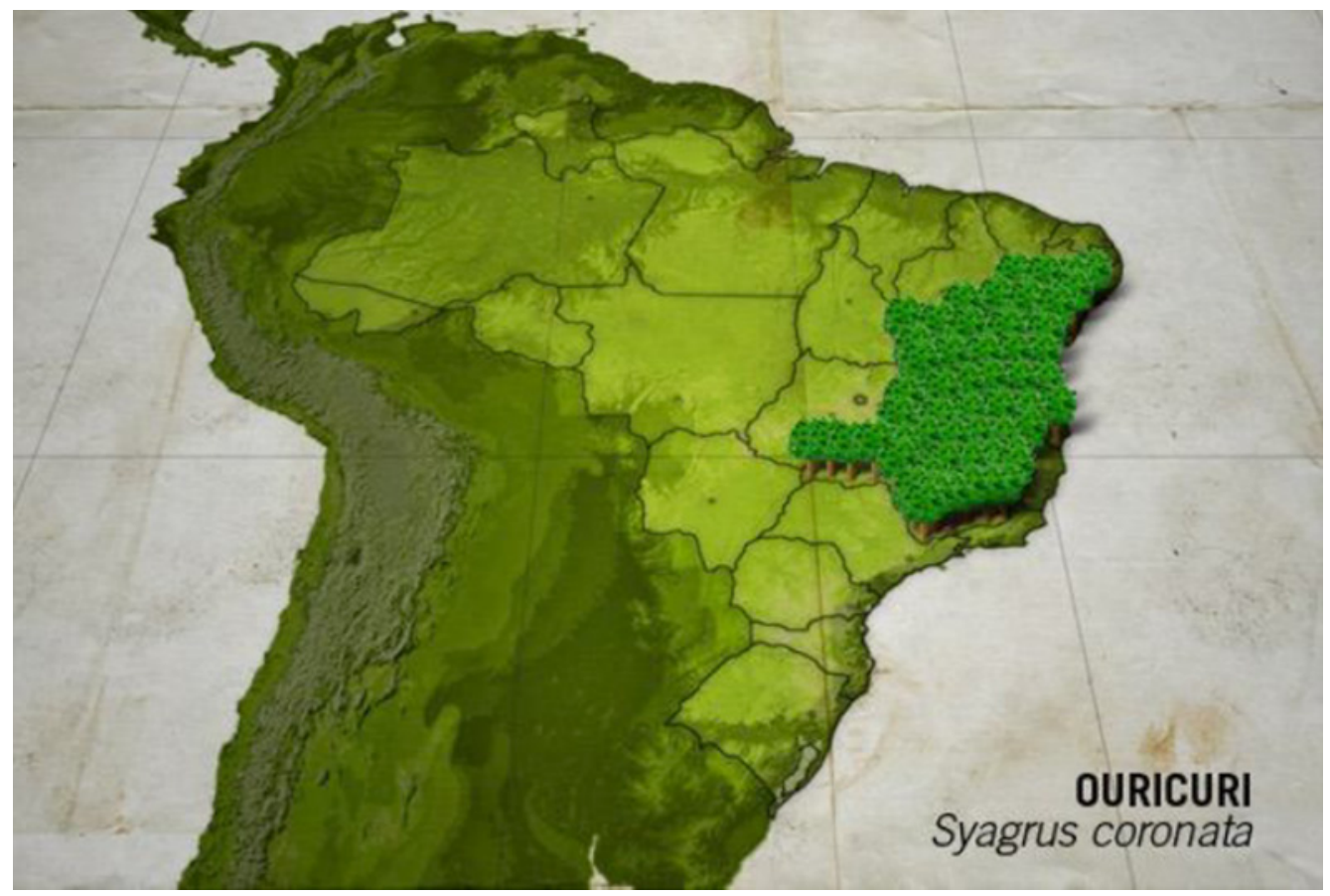

FIGURA 2 - Distribuição geográfica do licuri.

FONTE: Oliveira et al. (2013). 
(Beltrão \& Oliveira, 2007; Drumond, 2007). Normalmente cada planta apresenta um único estipe, sendo, portanto, muito raro encontrar pés de licuri com mais de um caule ou em touceiras (Figura 3) (Aroucha \& Aroucha, 2013).

Por não apresentarem uma raiz principal bem desenvolvida, mas sim uma grande quantidade de raízes retorcidas, juntas e profundas, isto lhes possibilitam ter uma vida mais longa (Beltrão \& Oliveira, 2007; Aroucha \& Aroucha, 2013; Carvalho et al., 2014).

Suas folhas surgem de forma continua, na parte mais alta do centro da copa, sempre em cinco fileiras, em sequência de espiral. O caule ou pecíolo foliar apresenta-se comprido e com formações fibrosas, semelhantes a espinhos, ao longo de suas margens (Beltrão \& Oliveira, 2007; Aroucha \& Aroucha, 2013). Demonstram flores dos dois sexos e em inflorescência, portanto, muitas flores juntas em um único cacho (Figura 3) (Beltrão \& Oliveira, 2007; Drumond, 2007; Aroucha \& Aroucha, 2013).
Cada licuri pode conceder até quatro cachos por ano que medem de 40 a $60 \mathrm{~cm}$ e são encaixados entre as folhas, apresentam-se ramificados, agrupados e protegidos por uma cimba, também chamada de catemba ou capemba, em forma de uma pequena canoa e pode crescer de $1 \mathrm{~m}$ de comprimento e 20 $\mathrm{cm}$ em sua parte mais larga (Beltrão \& Oliveira, 2007; Aroucha \& Aroucha, 2013).

Seus frutos são agrupados nos cachos e possuem formato oval, cada um deles com 2 a $3 \mathrm{~cm}$ de comprimento e aproximadamente $1,5 \mathrm{~cm}$ de diâmetro. A casca é formada por fibras e polpa, coberta por uma camada densa de cedas macias, que tem coloração variada. Os cachos que apresentam de 30 a $40 \mathrm{~cm}$ de comprimento, fornecem em média 1.350 frutos (Figura 4) (Beltrão \& Oliveira, 2007; Drumond, 2007; Aroucha \& Aroucha, 2013).

Enquanto verdes, os frutos possuem polpa interna líquida e leitosa, que se torna sólido no processo de amadurecimento, dando origem à amêndoa. Quando maduros, apresentam uma coloração

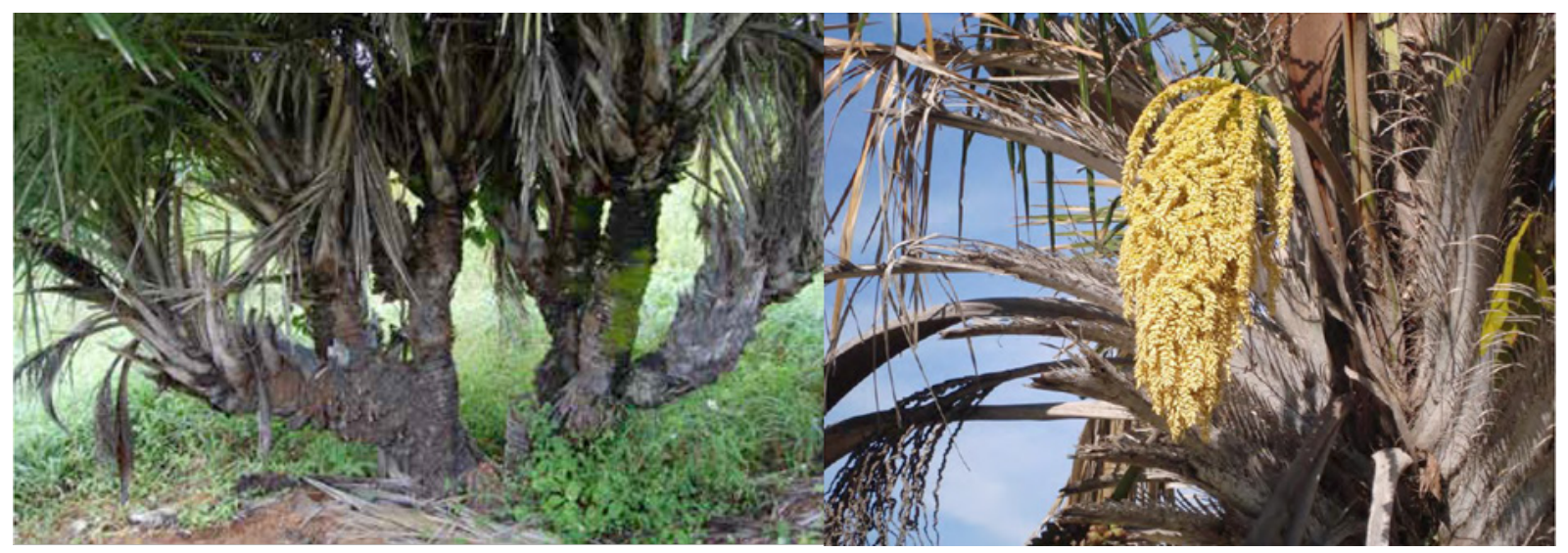

FIGURA 3 - Licurizeiros em touceiras e Inflorescência do licurizeiro.

FONTE: Miranda \& Silva (2011) e Aroucha \& Aroucha (2013) 
que varia do amarelo-claro ao laranja, dependendo de seu estágio de maturação e da planta que o produziu (Aroucha \& Aroucha, 2013; Oliveira et al., 2013). De acordo com Miranda \& Silva (2011), essa coloração do fruto é um bom indicativo para o ponto de colheita, sendo indicado que a maturidade no estádio amarelo claro é o mais adequado para a colheita (Figura 4).
Baseado em Miranda \& Silva (2011), Santos et al. (2011) e Oliveira et al. (2013), é possível identificar diferentes partes no fruto do licurizeiro (Figura 5). A epiderme ou exocarpo caracteriza-se pela superfície externa, lisa e cérea, envolve o fruto e sua cor varia dependendo da variedade e maturidade do fruto. $\mathrm{O}$ mesocarpo ou cairo trata-se da parte intermediária, caracterizado como a polpa
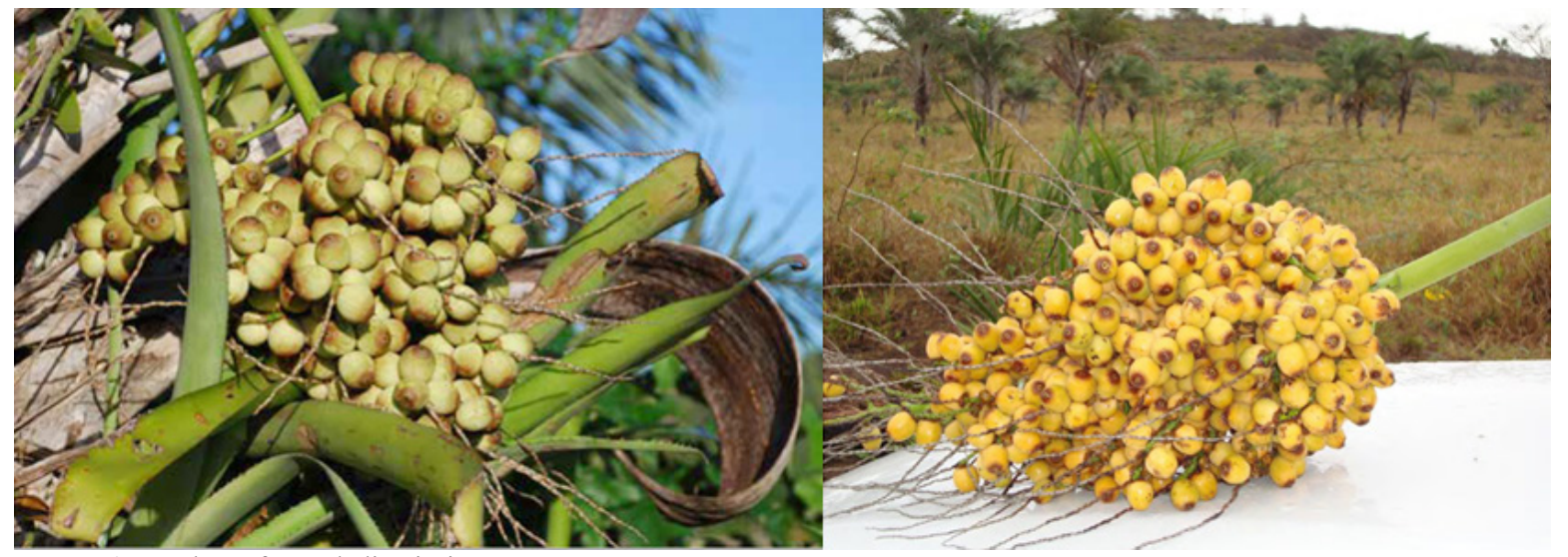

FIGURA 4 - Cachos e frutos do licurizeiro.

FONTE: Miranda \& Silva (2011) e Aroucha \& Aroucha (2013).

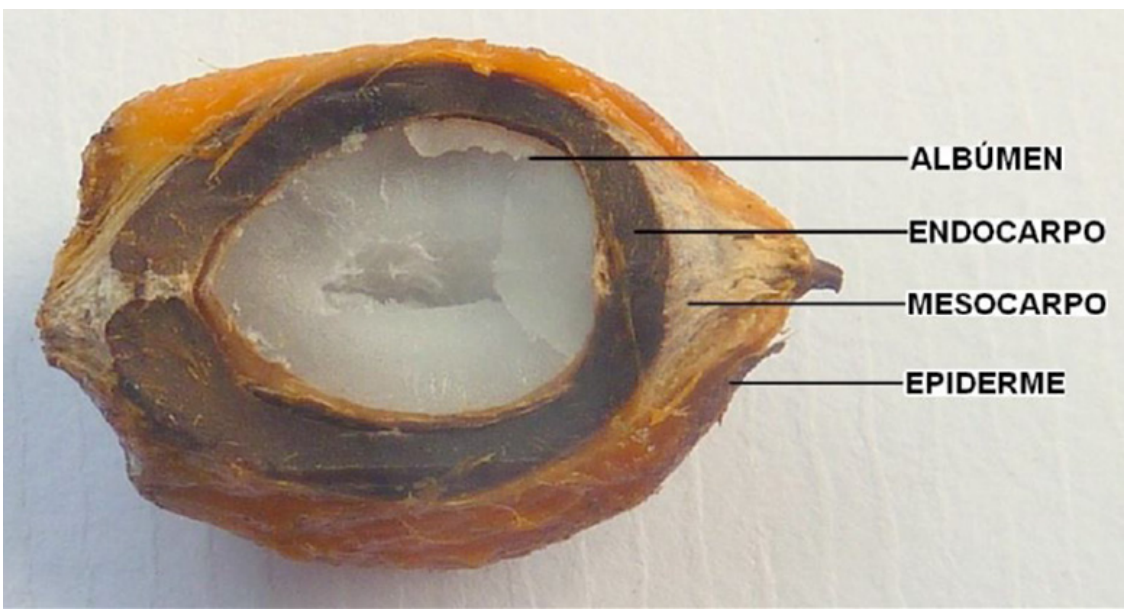

FIGURA 5 - Corte vertical do fruto do licurizeiro.

FONTE: Santos et al. (2011). 
fibrosa, mucilaginosa e geralmente apresenta a cor castanha. $\mathrm{O}$ endocarpo, também chamado de cáscara ou casca, trata-se do envoltório da amêndoa, demonstra a coloração negra, apresenta-se duro, espesso e resistente. Já o albúmen ou amêndoa é geralmente de cor branca brilhante e apresenta-se revestido por uma película chamada de tegumento.

$\mathrm{O}$ nascimento natural de novos licurizeiros acontece no entorno das palmeiras adultas, as sementes germinam de um ano para o outro ocorrendo, naturalmente, concorrência por água e nutrientes do solo. Ao desenvolverem-se em condições favoráveis, sem existência de secas demoradas, iniciam, em média, a floração e a produção de frutos aos seis anos e em apenas cinco anos já é possível a retirada de folhas para as diversas utilizações (Aroucha \& Aroucha, 2013; Carvalho et al., 2014).

Contudo, em condições desfavoráveis, em áreas de solos mais fracos e de vegetações mais degradadas, inclusive sofrendo com queimadas, presença de rebanhos em pastoreio livre e com poucas chuvas e irregulares, os licurizeiros tendem a diminuir suas produções (Aroucha \& Aroucha, 2013).

A floração e produção de cachos de frutos acontecem todos os anos, em muitos meses ou quase o ano todo, pois isso varia entre os pés de licuri, conforme idade, qualidade do solo e presença de outras plantas nativas, possuindo portanto, pouca sincronia de frutificação, garantindo alimento o ano todo (Carvalho et al., 2014). No entanto, podem existir diferenças dependendo da região e também de condições climáticas (Aroucha \& Aroucha, 2013).

Carvalho et al. (2014), durante seus trabalhos em campo, relatam ter visto em diversas localidades do Semiárido baiano, a morte de muitos licurizais acometidos por uma doença com sinais e sintomas semelhantes ao do anel vermelho, que promove a quebra da ráquis (pecíolo primário ou eixo central da planta), inflorescências e decomposição do estipe, comprometendo o vigor da planta e causando, muitas vezes, a perda total da palmeira. Além disso, os autores alertam que não existe renovação dos licurizais, podendo estes se tornarem raros ou até mesmo desaparecerem da região.

\subsection{Importância socioeconômica e cultural do licuri}

O licurizeiro denota-se como uma espécie de muita importância socioeconômica e cultural para os povos e comunidades tradicionais, agroextrativistas e agricultores familiares da região semiárida, principalmente para os que estão envolvidos na sua cadeia produtiva (coleta, processamento, industrialização e comercialização de seus produtos e derivados) (Aroucha \& Aroucha, 2013).

A planta apresenta todas as partes aproveitáveis: raízes, caule, todas as partes das folhas (bainhas, talos, palhas, fibras, talinhos, cera dos folíolos e capembas) e todo o fruto (polpa, endocarpo e amêndoa) (Beltrão \& Oliveira, 2007; Drumond, 2007; Aroucha \& Aroucha, 2013). Cooperando de maneira significante para a sobrevivência da população sertaneja e constituindo-se um fator essencial para a sustentabilidade da região (Rocha et al., 2009; Jesus \& Santos, 2017).

Seus usos são diversos: as folhas são usadas para construções, artesanatos diversos (chapéus, bolsas, esteiras, abanadores, vassouras e espanadores); os frutos são usados na alimentação humana e animal e para fabricação de artesanatos, sabões e óleos (Figura 6) (Rufino et al., 2008; Aroucha \& Aroucha, 2013; Carvalho et al., 2014). 
No entanto, é mais conhecido pelo seu uso tradicional em comidas e bebidas associadas a períodos litúrgicos como de Reis Magos, Semana Santa, Quaresma, festas de Santo Antônio, São João, São Pedro, Natal e datas especiais, como fim de ano, nascimentos, aniversários, batizados e casamentos (Aroucha \& Aroucha, 2013).

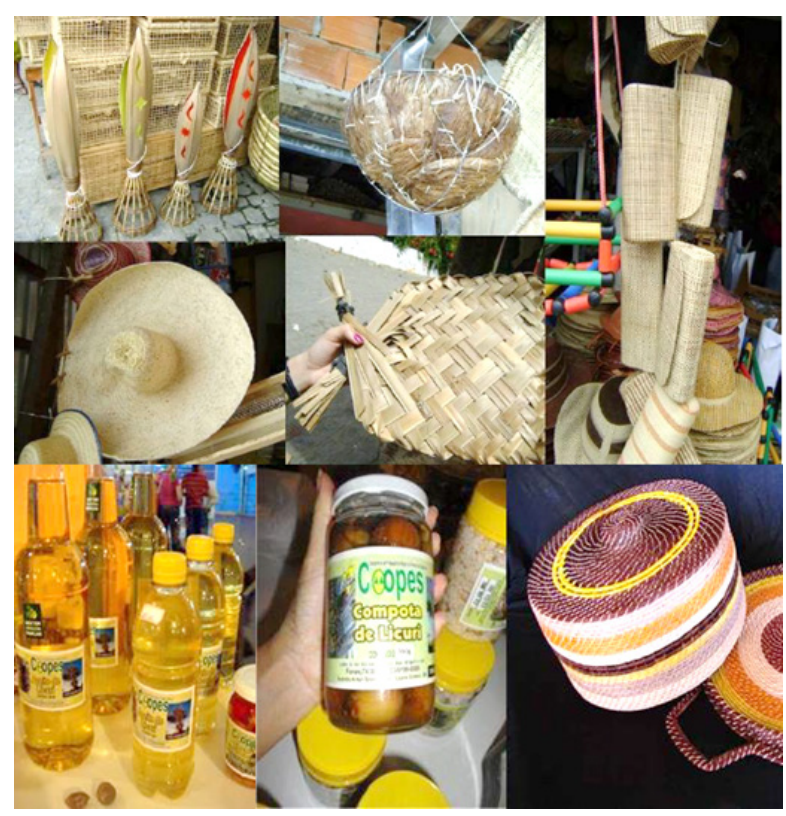

FIGURA 6 - Produtos originados do licuri.

FONTE: Silva et al. (2012) e Farias et al. (2013).

A utilização de suas folhas ou palhas in natura como forragem ou ração, trituradas junto com frutos e inflorescências, demonstra-se com uma das poucas alternativas para os criatórios, principalmente de bovinos, nos períodos de seca. Por motivos como esses, o licuri é reconhecido pelas comunidades locais como uma palmeira sagrada e é considerada como uma espécie forrageira de reserva estratégica em situações críticas (Aroucha \& Aroucha, 2013).
Há muito tempo também, o licuri serve de inspiração na composição de cantigas, versos, prosas populares e festejos em sua homenagem, espalhados por diversas cidades do Nordeste, principalmente no interior da Bahia (Figura 7) (Aroucha \& Aroucha, 2013; Carvalho et al., 2014).

Destaca-se entre um dos maiores produtores de licuri, o município baiano de Caldeirão Grande, com produção de aproximadamente 500 mil $\mathrm{Kg}$ anuais de seus 16 milhões de palmeiras, reforçando a importância deste alimento na economia das famílias da Caatinga (Aroucha \& Aroucha, 2013).

Sabe-se que existem diversas iniciativas coletivas voltadas para a utilização socioeconômica e sustentável do licuri. Dentre elas, destaca-se a Cooperativa de Produção da Região do Piemonte da Diamantina - COOPES, localizada na cidade de Capim Grosso - BA (Figura 7). Esta entidade agrega 234 cooperados, sendo formada em grande parte por mulheres $(80 \%)$, além da sua atuação ter impacto direto na vida de 450 famílias (COOPES, 2018). A COOPES é constituída por agricultores familiares que cultivam, coletam, beneficiam e comercializam produtos da sociobiodiversidade do Semiárido baiano, predominando os produtos derivados do licuri (biscoito, licor, azeite, granola, paçoca, cocada, pão, sorvete e leite de licuri); devido a sua proposta de trabalho, integra redes, fóruns e articulações da economia local e comércio justo e solidário (Slow Food, 2015).

Essa cooperativa agregou o licuri em cardápios escolares de alguns municípios, adicionado na composição de bolachas e em outros produtos. Além de levar o licuri para o exterior, obtendo grande aceitação e divulgação na Salone Del Gusto, um evento realizado bienalmente na cidade de Turim, na Itália, onde ficou conhecido como "coco picolo 
di Brasile", pequeno coco do Brasil (Carvalho et al., 2014). Participando, portanto, da filosofia do alimento limpo e do comércio justo e solidário, preconizado pelo movimento internacional Slow Food, ao qual a COOPES encontra-se associada, desenvolvendo atividades de educação ambiental, preservação, resgate de tradições, promoção, divulgação e fortalecimento da comercialização dos produtos beneficiados do licuri (Slow Food, 2015).

Ademais, merece destaque também, a Associação de Artesãos de Santa Brígida - AASB, que desde o ano de 2001 reúne cerca de 40 famílias para possibilitar a geração de renda para as comunidades através da produção dos artesanatos do licuri (Aroucha \& Aroucha, 2013). Contudo, esses autores, alertam que apesar dessas novas oportunidades de trabalho e de geração de renda, ainda existe muito a se fazer para serem aproveitadas de forma adequada, pois muitos agricultores familiares não se atentaram ao potencial da cadeia econômica do licuri ou não dispõem de meios necessários para investir em uma produção organizada ou para acessar melhores mercados.

Dentre esses potencias socioeconômicos do licuri, Oliveira \& Carvalho (2010), ao analisarem as propriedades da fibra dos segmentos foliares do licuri, sugerem que estas apresentam potencial de aplicação e utilização como fibra na composição de compósitos utilizados em construção civil. Já Silva et al. (2015) avaliaram a capacidade de absorção desta fibra in natura na remoção do corante azul de metileno, demonstrando que esse resíduo agroindustrial é um atrativo na remediação deste corante, tanto do ponto de vista de eficiência do processo quanto em relação ao seu baixo custo.

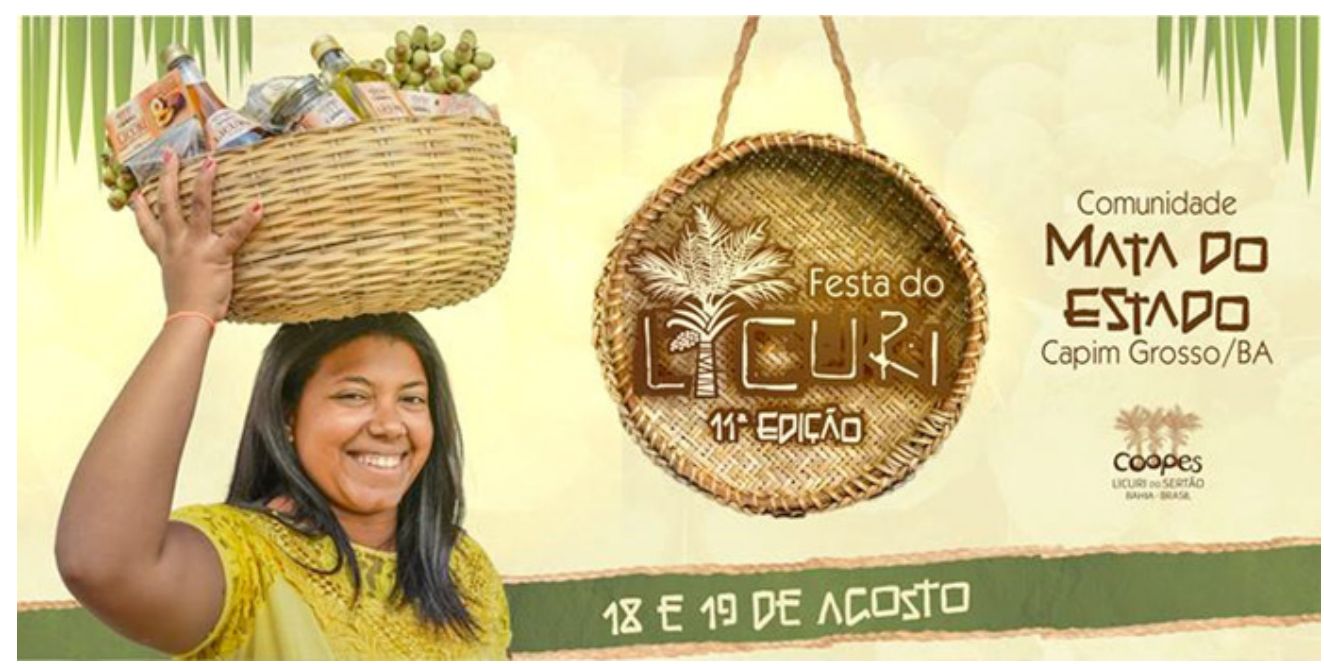

FIGURA 7 - Festa do licuri.

FONTE: COOPES (2018). 
Por sua vez, o caule ou estipe, quando ocorre a morte do licurizeiro, pode ser utilizado como lenha, principalmente nas localidades onde existe pouca lenha disponível ou não existem outros tipos de biocombustíveis sólidos de origem vegetal (Aroucha \& Aroucha, 2013).

Entre suas mais diversas utilidades, com o advento dos biodieseis, o potencial do licuri despertou interesse, por parte de produtores rurais, em manejar os licurizais naturais ou até mesmo em estabelecer novos plantios para fins dessa produção (Drumond, 2007). Por conta disso, Oliveira et al. (2013) mostraram que o licuri apresenta uma biomassa com potencial uso como fonte alternativa para obtenção de energia, pois agrega uma quantidade de energia considerável e comparável a outras biomassas utilizadas.

Santos et al. (2011), ao avaliarem as propriedades físico-químicas, fluidodinâmicas e oxidativas do biodiesel de licuri, observaram também que as características físico-químicas do óleo de licuri apresentaram boas condições para a obtenção do biodiesel. Concluíram, além disso, que o biodiesel de licuri demonstrou ótimo perfil como biocombustível, sendo capaz de ser usado diretamente em motor diesel ou como mistura para outro tipo de biodiesel ou petrodiesel.

Desse modo, Carvalho et al. (2014), descreveram que essa influência mútua que ocorre entre homem e licuri, associada ao etnoconhecimento, agregando saberes, cultura, relações, conhecimento e o manejo dos recursos naturais, apresenta impacto direto na vida dos sertanejos e, consequentemente, na distribuição geográfica e econômica do licuri.

\subsection{Importância ecológica e ambiental do licuri}

O licurizeiro é uma palmeira de indispensável importância ecológica para diversas espécies de aves (como araras, maracanãs, papagaios e periquitos) e mamíferos roedores silvestres (como cotias, mocós, préas, punarés, rabudos e outros), que se alimentam de seus frutos (Aroucha \& Aroucha, 2013).

Dentre as aves para as quais as amêndoas do licuri são alimentos importantes, destacam-se duas espécies de araras: arara-azul-de-lear (Anodorhynchus leari) e ararinha-azul (Cyanopsitta spixii) (Aroucha \& Aroucha, 2013; Lima et al., 2014). A arara-azul-de-lear, por ser muito cobiçada pelos traficantes, está classificada como uma espécie criticamente ameaçada de extinção (Figura 8). A ararinha-azul, por sua vez, de tão caçada e traficada, já não existe mais na natureza (Farias et al., 2013; Slow Food, 2015).

Baseado nisso, Lima et al. (2014) desenvolveram um estudo que teve como objetivo identificar novos itens alimentares utilizados pela arara-azul-de-lear e descrever seu comportamento alimentar no licurizeiro. Considerando, portanto, o fato que a arara-azul-de-lear é endêmica da Caatinga baiana e encontra-se ameaçada de extinção em virtude da perda de habitat e do tráfico internacional, em vista disso, informações sobre sua dieta são importantes para a tomada de medidas voltadas para a conservação dessa espécie.

Os autores registraram sete itens alimentares consumidos pelas araras: sementes do milho (Zea mays), frutos de baraúna (Schinopsis brasiliensis), frutos de mandacaru (Cereus jamacaru), sementes de umbuzeiro (Spondias tuberosa), sementes de 
pinhão-bravo (Jatropha pohliana), sementes de licuri e conchas do caramujo Megalobulimus sp. (Lima et al., 2014).

O consumo de mandacaru pelas araras, por sua vez, sugere que este pode ser um recurso alimentar importante nos períodos de baixa produtividade do licuri. Contudo, se fazem necessários mais esforços na identificação de registros como este na natureza, para permitir concluir se realmente o mandacaru apresenta-se como uma fonte alimentar complementar ou alternativa para a arara-azul-de-lear (Lima et al., 2014). Os autores concluem, portanto, que tais resultados podem direcionar ações que visem incentivar o plantio de espécies nativas, favorecer a redução dos ataques de araras aos milharais, além de levantar hipóteses que incentivem à realização de novos estudos com o objetivo de conciliar a presença destas aves com as plantações, sem causar prejuízos ao homem.

De acordo com Aroucha \& Aroucha (2013), um diagnóstico feito em conjunto pelo Centro Nacional de Pesquisa para Conservação das Aves Silvestres - CEMAVE, do Instituto Chico Mendes de Conservação da Biodiversidade - ICMBio e pela ONG PROAVES, constatou as condições dos licurizais na região do Raso da Catarina-BA, com objetivo de avaliar o ambiente de sobrevivência das araras. Foi realizado o mapeamento de 37 locais onde se verificou baixa capacidade de regeneração natural da palmeira, alta taxa de senescência, onde

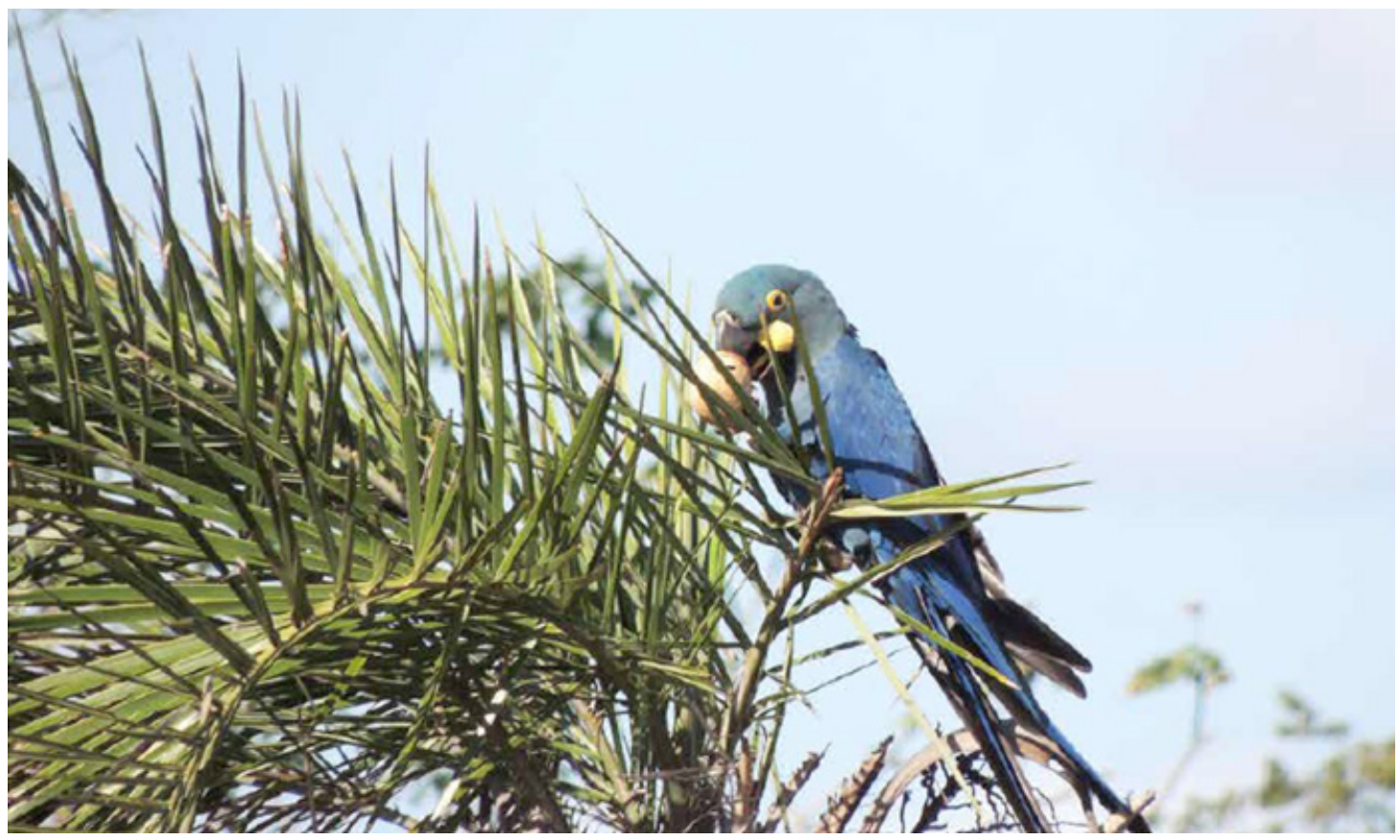

FIGURA 8 - Arara-azul-de-lear (Anodorhynchus leari).

FONTE: Lima et al. (2014). 
muitos pés estão velhos e em fase final dos seus ciclos de vida, além de baixo percentual de proteção desses licurizeiros, onde apenas 5,4\% apresentam-se localizados em unidades de conservação.

Os autores ressaltam, que a sobrevivência dessas espécies nativas e silvestres dependem da conservação e da utilização sustentável do licuri, portanto, sua degradação reduz a disponibilidade de alimentos para esses animais, contribuindo para sua extinção (Aroucha \& Aroucha, 2013). Além disso, essas espécies também atuam como disseminadoras do licuri, principalmente os mamíferos roedores (cotias, mocós, préas, punarés, rabudos e outros) ao guardarem enterradas algumas sementes, essas acabam germinando. Os caititus, emas e animais de criatórios (bois, cabras, ovelhas, cavalos, jumentos, burros e porcos), que ao se alimentarem dos frutos, mastigam e digerem a casca e polpa, liberando as sementes por meio de regurgitamento e fezes (Aroucha \& Aroucha, 2013).

Já dentre os agentes polinizadores do licuri, encontram-se frequentemente abelhas arapuás (Trigona spinipes). Além de serem identificados também insetos associados ao licurizeiro, o mais recorrente é o Pachymerus nucleorum (Figura 9) (Carvalho et al., 2014).

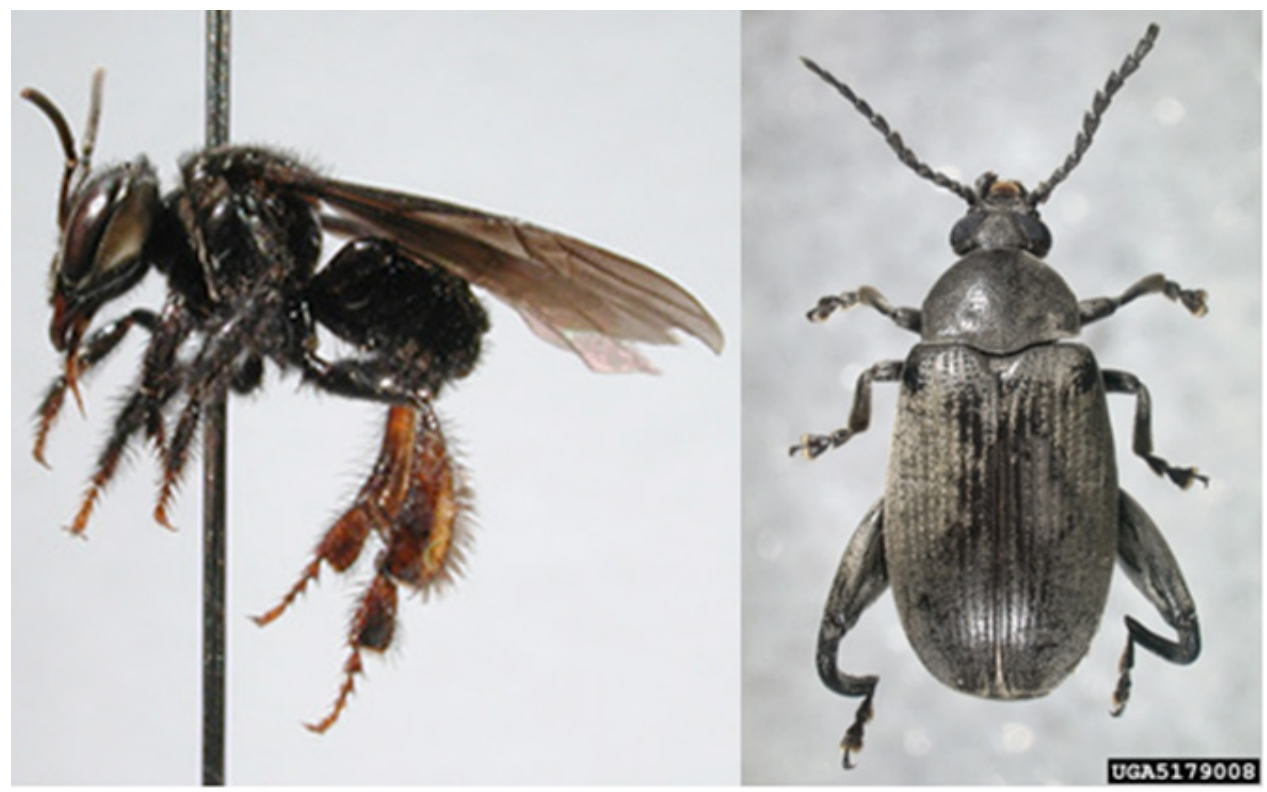

FIGURA 9 - Abelha arapuá (Trigona spinipes) e Pachymerus nucleorum. FONTE: Carvalho et al. (2014) e Slow Food (2015). 
Destaca-se, ainda, o fato de que estão habitualmente associadas ao licurizeiro, espécies de plantas chamadas de caroneiras ou epífitas (como briófitas, pteridófitas e angiospermas, principalmente as bromeliáceas, cactáceas, orquidáceas e euforbiáceas), que se fixam nas bainhas foliares e em partes do caule (estipe) da palmeira, onde também se agrupam líquens (associações entre fungos e algas), que são mais vistos nos períodos chuvosos (Figura 10) (Aroucha \& Aroucha, 2013; Carvalho et al., 2014).

Oliveira et al. (2015), estudaram a ecologia e composição florística dos epífitos vasculares em espécimes de licurizeiro, verificando que além da já reconhecida importância socioeconômica do licuri para o Semiárido brasileiro, também se apresenta como um forófito de elevada importância na manutenção da comunidade epifítica da Caatinga, uma vez que serve de sítio para o desenvolvimento e reprodução de diversas espécies de hábito obrigatoriamente epifítico.

Ademais, Carvalho et al. (2014) relatam que uma prática frequentemente observada foi a de despalma (corte das folhas) do licurizeiro para a alimentação do gado durante os períodos de seca prolongada. E que, portanto, foi sistematizada uma proposta, quanto ao manejo dos licurizais, em diálogos entre técnicos e camponeses, para evitar a remoção excessiva de palhas e regular o pastejo de animais de modo que seja permitida a renovação das palmeiras. Ressaltam ainda, que na formação de pastagens o licuri é uma espécie altamente adaptável às condições de sistemas agrossilvopastoris.

A pecuária extensiva (criatórios de bovinos, caprinos e ovinos) é uma ameaça identificada nos sítios de alimentação das araras, já que esses animais ao se alimentarem das folhas verdes e jovens de licuris e de amêndoas maduras, levam à diminuição da quantidade de frutos que poderiam desenvolver novas palmeiras. Além disso, os desmatamentos ilegais, queimadas e ampliação de minerações também são grandes ameaças aos licurizais (Aroucha \& Aroucha, 2013).

Silva et al. (2012), com o objetivo de avaliar o potencial nutricional de seis espécies de Arecaceae

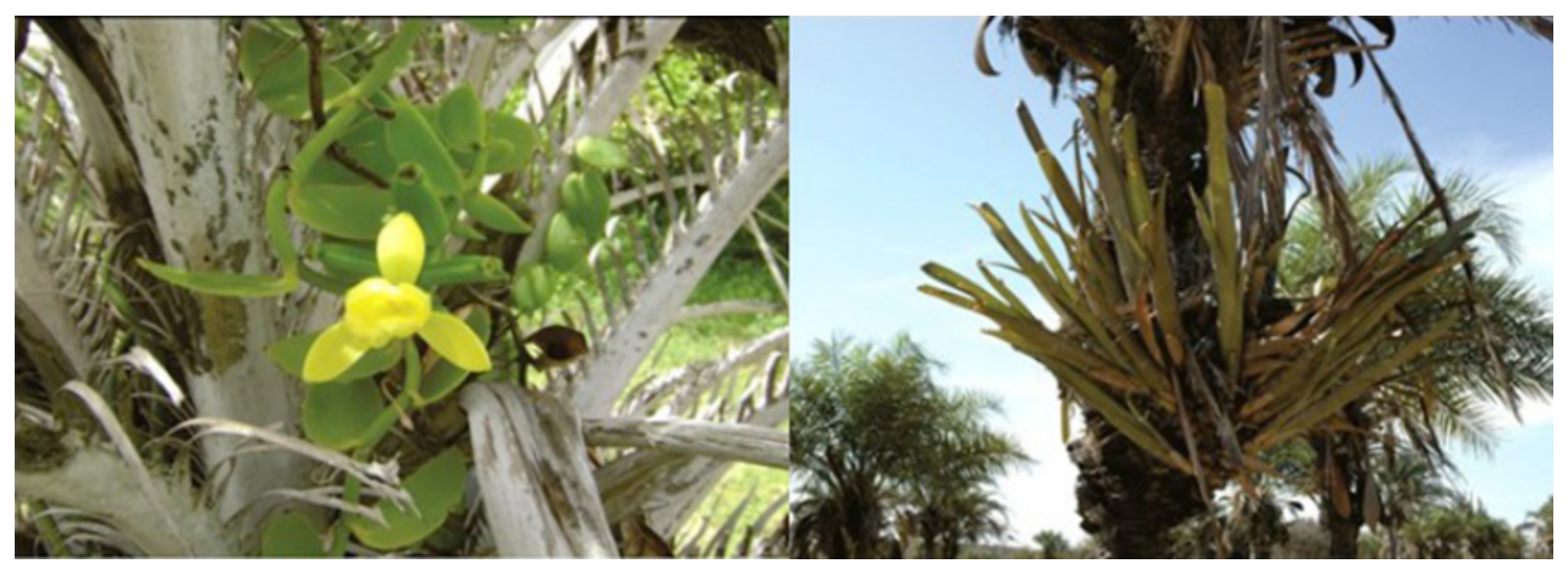

FIGURA 10 - Plantas epífitas associadas ao licurizeiro.

FONTE: Oliveira et al. (2015). 
ocorrentes em Pernambuco, concluíram que apesar dessas espécies serem potencialmente úteis, seu estudo reforça o bom uso, manejo e conservação das espécies nativas em locais onde ocorrem de modo espontâneo, visto que estão ameaçadas, devido a essas alterações em seu ambiente natural, diminuindo o tamanho das populações naturais.

A Slow Food (2015) destaca que para fortalecer a preservação do licurizeiro, é fundamental conhecer seus produtos e valorizar os produtores. Essas ações são essenciais e podem ser destinadas também para outras espécies, colaborando com a agrobiodiversidade, gerando demandas para a agricultura familiar, favorecendo os pequenos produtores e a cultura tradicional.

Apesar disso, estudos apontam que devido ao teor de ácidos graxos presentes nas amêndoas do licuri, principalmente o ácido graxo láurico, pode-se proporcionar a redução da produção e concentração de metano e amônia no rúmen desses animais, sendo assim, empregadas com sucesso no enriquecimento de rações. O que poderia contribuir, portanto, para a diminuição da formação de gases de efeito estufa por parte desses animais (Mohammed et al., 2004; Miranda \& Silva, 2011).

A palmeira encontra-se entre as espécies prioritárias para o enriquecimento de pastos, formações de agroflorestas e recuperação de áreas degradadas, além de apresentar também um grande potencial paisagístico, surgindo cada vez mais em ornamentações e paisagismo de moradias, parques, praças e avenidas (Aroucha \& Aroucha, 2013; Carvalho et al., 2014). Devido tudo isso e seus muitos benefícios ecológicos e ambientais para o Semiárido, o licuri é considerado uma "espécie-chave" do bioma Caatinga (Rocha et al., 2009), por isso que seu corte é proibido por normas federais e municipais como Instrução Normativa Ibama n ${ }^{\circ} 191$, de 24 de setembro de 2008; Lei ${ }^{0} 767 / 2013$, do município de Mairi - BA; Lei no 292/2014 do município de Capim Grosso - BA e Projeto de Lei n ${ }^{\circ}$ 04/2005, do município de Antônio Gonçalves - BA (Aroucha \& Aroucha, 2013).

\subsection{Potencial alimentício e nutricional do licuri}

Sabe-se que frutos de algumas palmeiras apresentam potencial oleaginoso, fornecendo importantes óleos. Além do teor de lipídios, sementes de várias espécies de palmeiras são usadas na alimentação humana e animal por apresentarem considerável valor nutritivo, consumidos tanto in natura como após processados (Silva et al., 2012).

No caso do licuri, por ser uma palmeira totalmente aproveitável, é amplamente explorada desde os primórdios da colonização portuguesa (Drumond, 2007; Jesus \& Santos, 2017). Conforme informação presente no Tratado Descritivo do Brasil (1587), de Gabriel Soares de Souza, considerada a primeira notícia sobre o licuri, relatando sua utilização na alimentação pela população local (Oliveira \& Carvalho, 2010; Carvalho et al., 2014). Desde então, a importância do licuri na alimentação aumenta e, cada vez mais, novas receitas são elaboradas (Aroucha \& Aroucha, 2013).

A amêndoa do licuri habitualmente é consumida in natura e vendida em cordões chamados rosários ou processada em diversos produtos, sendo utilizada para produzir farinha, beiju, pão, biscoito, cuscuz, bolo, torta, doce, granola, barra de cereal, cocada e paçoca (Figura 11) (Antoniassi et al., 2005; Rufino et al., 2008; Aroucha \& Aroucha, 2013). 
Dessas, ainda pode ser extraído o sumo, chamado de "leite do licuri", que é utilizado principalmente para fazer comidas tradicionais (como umbuzadas, peixadas, moquecas, cuscuz, tapioca, feijão, arroz, bredo, peixe ou bacalhau), além de ser usada para fabricação (caseira ou industrial) de licores, picolés, sorvetes e bolos (Antoniassi et al., 2005; Rufino et al., 2008; Aroucha \& Aroucha, 2013).

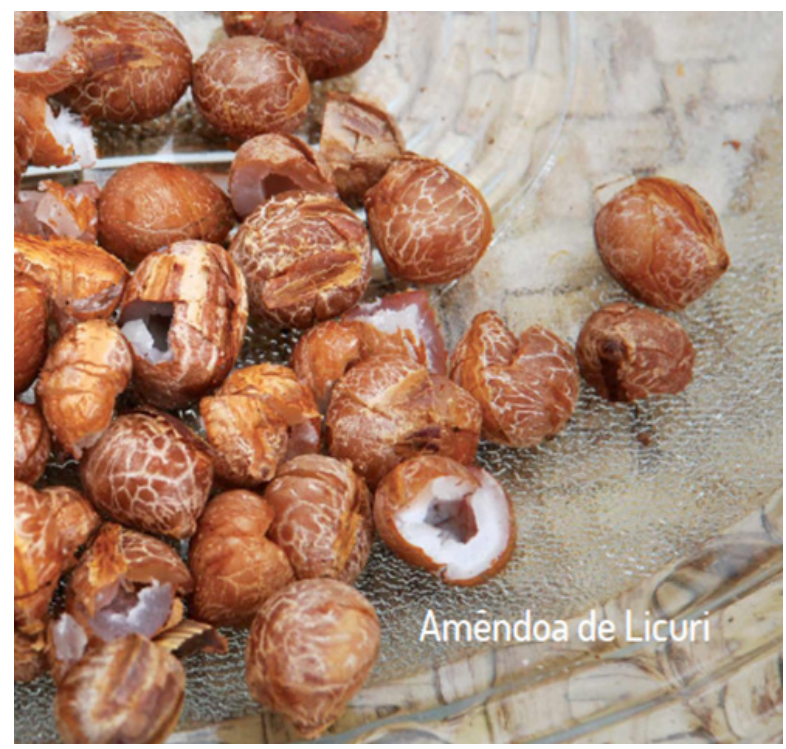

FIGURA 11 - Amêndoa do licuri. FONTE: Slow Food (2015).
Além disso, comumente utiliza-se a larva do inseto Pachymerus nucleorum, conhecida como lagarta-do-coco, como alimento tradicional (Figura 12). Esta se desenvolve dentro do endocarpo do licuri, alimentando-se da amêndoa (Figura 5) (Ramos-Elorduy et al., 2006; Aroucha \& Aroucha, 2013).

Ramos-Elorduy et al. (2006) ao realizarem um estudo comparativo do valor nutricional de besouros comestíveis do México e do P. nucleorum do licuri, concluíram que estes possuem um alto valor nutricional em proteínas, aminoácidos, lipídios, calorias e minerais. $P$. nucleorum apresentou $33,05 \%$ de proteínas, $49,32 \%$ de gorduras, $11,50 \%$ de carboidratos, $3,22 \%$ de minerais, $2,91 \%$ de fibras e 621,0 $\mathrm{Kcal} / 100 \mathrm{~g}$, portanto seu consumo contribui para a nutrição das populações que os consomem de forma adequada.

O P. nucleorum pode ser consumido cru, junto com a amêndoa, frito no azeite de licuri ou preparado com farofa, sendo que seu sabor remete ao da amêndoa e é descrito como delicado e requintado. Avalia-se que ao consumir a amêndoa, os lipídios que a compõem são absorvidos e biotransformados na própria larva (Ramos-Elorduy et al., 2006; Aroucha \& Aroucha, 2013).
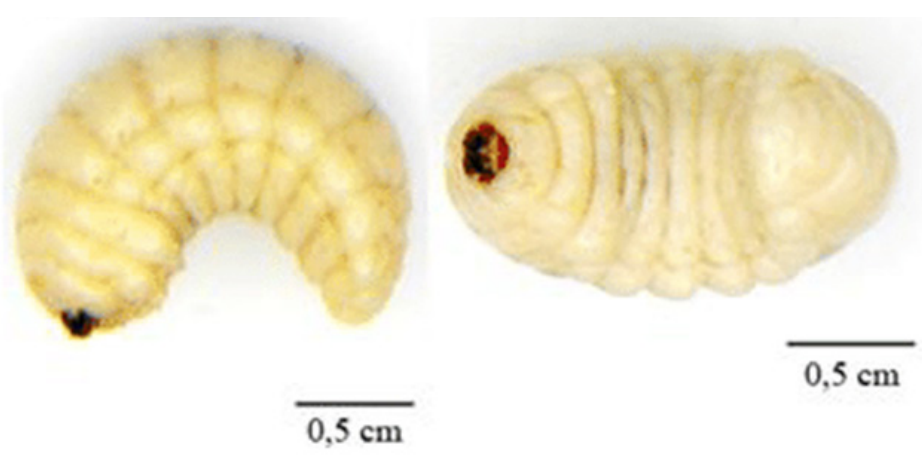

FIGURA 12 - Lagarta-do-coco (Pachymerus nucleorum).

FONTE: Aroucha \& Aroucha (2013). 
O azeite das amêndoas, extraído pela prensagem a frio, apresenta uma crescente utilização na culinária, principalmente por chefs de cozinha de restaurantes renomados que buscam alimentos da sociobiodiversidade para elaboração de receitas especiais e saudáveis (Aroucha \& Aroucha, 2013).

Observa-se que na composição nutricional do licuri, merecem destaque o teor de lipídios e de proteínas da amêndoa e o teor de carboidratos totais da polpa (Crepaldi et al., 2001; Santos et al., 2014a).

A amêndoa do licuri apresenta um alto teor de óleo, que pode variar de 61 a $66 \%$, sendo predominante o ácido graxo láurico, que pode chegar a representar em torno de $50 \%$ do seu óleo, seguido do mirístico, caprílico e oleico, muito semelhante ao perfil lipídico do coco (Cocos nucifera) (Antoniassi et al., 2005; Folegatti et al., 2006).

Os teores de proteína e fibras variam de 8 a $10 \%$ e de 13 a 15\%, respectivamente. Já os minerais prevalentes são potássio (508 a $517 \mathrm{mg} \cdot 100 \mathrm{~g}^{-1}$ ), fósforo (325 a $346 \mathrm{mg} \cdot 100 \mathrm{~g}^{-1}$ ), magnésio (132 a 162 mg.100g $\left.\mathrm{g}^{-1}\right)$, cálcio (33 a $\left.36 \mathrm{mg} \cdot 100 \mathrm{~g}^{-1}\right)$, cobre $(0,98$ a $\left.1,08 \mathrm{mg} \cdot 100 \mathrm{~g}^{-1}\right)$, manganês $\left(2,3\right.$ a $\left.3,5 \mathrm{mg} \cdot 100 \mathrm{~g}^{-1}\right) \mathrm{e}$ ferro (2,6 a 3,2 mg.100g-1) (Antoniassi et al., 2005; Folegatti et al., 2006).

De acordo com Crepaldi et al. (2001), esse teor lipídico da amêndoa é elevado e similar ao padrão encontrado em outras espécies de palmeiras. Silva et al. (2012), que analisaram o potencial nutricional de seis espécies de Arecaceae ocorrentes no Estado de Pernambuco, confirmaram prevalência de 44,55\% de ácido láurico (C12:0), 19,04\% de ácido mirístico (C14:0), 13,44 \% de ácido oléico (C18:1-cis) e 10,03 $\%$ de ácido palmítico (C16:0).

Já Miranda \& Silva (2011) ao realizarem avaliações físico-químicas da amêndoa do licuri colhidos no estádio de maturação predominante amarelo claro, chegaram à seguinte caracterização: $29,77 \%$ de umidade, $1,14 \%$ de cinzas, $4,93 \%$ de proteínas, $48,40 \%$ de lipídeos, 3,85\% de amido e 10,80\% de fibras. Além disso, ao analisarem o teor de ácido ascórbico (vitamina C), minerais e fenólicos presentes na amêndoa do licuri também colhidos no estádio de maturação predominante amarelo claro, chegaram na seguinte composição: $0,88 \mathrm{mg} \cdot 100 \mathrm{~g}^{-1}$ de ácido ascórbico, 1,05 mg. $100 \mathrm{~g}^{-1}$ de ferro, 326,23 mg.100 $\mathrm{g}^{-1}$ de potássio, $16,06 \mathrm{mg} \cdot 100 \mathrm{~g}^{-1}$ de sódio e $4,92 \mathrm{mg} \cdot 100 \mathrm{~g}^{-1}$ de zinco e 199,89 mg. $100 \mathrm{~g}^{-1}$ de fenólicos.

Os fenólicos, compostos amplamente encontrados na natureza, alguns dos quais exercem também função de antioxidantes naturais, foram encontrados em maior conteúdo na amêndoa desengordurada do que na polpa $\left(123,06 \mathrm{mg} 100 \mathrm{~g}^{-1}\right)$. Já ao avaliarem a atividade antioxidante dessas amêndoas desengorduradas, através do acréscimo no valor médio do $\mathrm{EC}_{50}$ (quantidade em g necessária para reduzir $50 \%$ da concentração inicial do 1,1'-diphenil-2-picrilhidrazil - DPPH em g.gDPPH ${ }^{-1}$ ), obtiveram valor igual a 68,72 g.gDPPH ${ }^{-1}$, portanto com atividade antioxidante muito superior também à polpa $\left(382,12\right.$ g.gDPPH $\left.{ }^{-1}\right)$, Miranda \& Silva (2011) concluem que a amêndoa é um alimento de baixa acidez, portanto, mesmo contendo um alto teor de lipídeos, o processo de rancificação seria mais lento, além de se apresentar como fonte expressiva de lipídeos, proteínas, fibras, potássio, sódio, polifenóis e propriedades funcionais importantes.

Silva et al. (2012), por sua vez, verificaram que os menores conteúdos de carotenoides em seu estudo, foram encontrados nas amêndoas de espécies de Syagrus, ambas com $7 \mu \mathrm{g} / \mathrm{g}$. Os autores afirmam que as duas espécies (Syagrus coronata e Syagrus cearenses) podem ser consideradas excelentes para a alimentação humana, com destaque para o licuri, pois lipídios, proteínas e carboidratos estão presentes em quantidades 
satisfatórias nas amêndoas. Porém, apenas sua polpa demonstra-se como fonte satisfatória de carotenoides $\left(8.706 \mu \mathrm{g} .100 \mathrm{~g}^{-1}\right)$.

Esses compostos são pigmentos lipossolúveis, amarelos, laranjas e vermelhos, presentes em muitas frutas e vegetais e que apresentam função antioxidante. Os exemplos mais comuns são: licopeno, $\alpha$ e $\beta$-caroteno, luteína, zeaxantina, capsantina e bixina. Alguns dos carotenoides apresentam a estrutura cíclica $\beta$-ionona em suas moléculas sendo, portanto, precursores de vitamina A (Silva et al., 2010). Segundo Crepaldi et al. (2001), o $\beta$-caroteno é a principal vitamina encontrada na polpa de licuri.

Santos et al. (2014a), ao avaliarem a composição centesimal da farinha do licuri, demonstraram que o baixo teor de umidade encontrado indica um favorecimento na conservação desse produto e na vida de prateleira. Considerando, portanto, que a farinha de licuri é um produto estável, pois sua baixa quantidade de água prejudica o crescimento e proliferação de microrganismos. Além disso, demonstraram que a farinha de licuri mantém o alto teor lipídico na sua composição, sendo também o principal macronutriente encontrado. Já a quantidade média dos ácidos graxos majoritários foi: láurico $\left(229,69 \mathrm{mg} \cdot 100 \mathrm{~g}^{-1}\right)$, oleico (98,44 mg.100 g $\left.{ }^{-1}\right)$, mirístico $\left(95,88 \mathrm{mg} \cdot 100 \mathrm{~g}^{-1}\right)$, palmítico $\left(55,16 \mathrm{mg} \cdot 100 \mathrm{~g}^{-1}\right)$, esteárico $\left(31,89 \mathrm{mg} \cdot 100 \mathrm{~g}^{-1}\right)$, linoleico $\left(21,20 \mathrm{mg} \cdot 100 \mathrm{~g}^{-1}\right)$, cáprico $\left(20,66 \mathrm{mg} \cdot 100 \mathrm{~g}^{-1}\right)$ e caprílico $\left(17,67 \mathrm{mg} \cdot 100 \mathrm{~g}^{-1}\right)$. Sendo a média dos ácidos graxos saturados de 450,96 mg.100 g ${ }^{-1}$ e dos ácidos graxos insaturados $119,64 \mathrm{mg} \cdot 100 \mathrm{~g}^{-1}$.

Ao considerar os resultados positivos da análise sensorial realizada, as autoras observaram que as formulações com diferentes níveis de substituição da farinha branca por farinha de licuri, podem ser utilizadas na preparação de bolos e biscoitos, bem como em outros produtos alimentícios, agregando valor nutricional.

Já Santos et al. (2014b) caracterizaram a farinha de licuri quanto à presença de compostos fenólicos totais e fibras solúveis e insolúveis, apontando que a farinha de licuri representa um importante alimento fonte de fibras insolúveis $(34,11 \%)$ e com quantidades satisfatórias de compostos fenólicos $(13,38$ mg.100g ${ }^{-1}$ ).

Ademais, Feltrin et al. (2014) apresentaram benefícios do ácido láurico na redução da ingestão calórica, apontando que essa substância age como um redutor natural do apetite, com o mesmo potencial de alguns medicamentos existentes. Entretanto, a inclusão deste ácido graxo saturado deve estar associada a um padrão alimentar saudável e à prática regular de atividade física para que esses benefícios sejam alcançados.

Não obstante, a Sociedade Brasileira de Cardiologia - SBC (2017), alerta que o consumo exagerado de ácidos graxos saturados da dieta relaciona com a elevação da trigliceridemia, por aumentarem a lipogênese hepática e a secreção de VLDL (lipoproteínas de muito baixa densidade). Desta forma, recomenda a inclusão maior de ácidos graxos poli e monoinsaturados na alimentação.

Santana et al. (2011), ao desenvolverem um estudo com objetivo de ampliar o conhecimento acerca da composição nutricional do licuri e de seus produtos derivados, apresentaram alguns resultados discordantes dos encontrados por outros autores, como Crepaldi et al. (2001), concluindo que a partir desse trabalho, e de outros existentes sobre este assunto, o licuri ainda possui um grande potencial nutricional a ser explorado.

Para mais, encontram-se descritas nas Tabelas 1 e 2 , as caracterizações das principais pesquisas que analisaram a composição centesimal do licuri e o perfil em ácidos graxos do licuri, respectivamente. 
TABELA 1 - Composição centesimal do licuri.

\begin{tabular}{|c|c|c|c|c|c|c|c|c|c|c|c|c|}
\hline AUTORES & $\begin{array}{c}\text { PARTE } \\
\text { ANALISADA }\end{array}$ & $\begin{array}{l}\text { UMI } \\
(\%)\end{array}$ & $\begin{array}{l}\text { CIN } \\
(\%)\end{array}$ & $\begin{array}{l}\text { CHO } \\
(\%)\end{array}$ & $\begin{array}{l}\text { LIP } \\
(\%)\end{array}$ & $\begin{array}{l}\text { PTN } \\
(\%)\end{array}$ & $\begin{array}{l}\text { FIT } \\
(\%)\end{array}$ & $\begin{array}{l}\text { FIS } \\
(\%)\end{array}$ & $\begin{array}{l}\text { FII } \\
(\%)\end{array}$ & $\begin{array}{l}\text { FET } \\
(\mathrm{mg})\end{array}$ & $\begin{array}{l}\text { CT } \\
(\mu \mathrm{g})\end{array}$ & $\begin{array}{c}\mathrm{VC} \\
\text { (kcal) }\end{array}$ \\
\hline \multirow[t]{2}{*}{ Crepaldi et al. (2001) } & Amêndoa & 28,60 & 1,20 & 9,70 & 49,20 & 11,50 & NA & NA & NA & NA & ND & 527,30 \\
\hline & Polpa & 77,40 & 1,40 & 13,20 & 4,50 & 3,20 & NA & NA & NA & NA & 26,10 & 108,60 \\
\hline Miranda \& Silva (2011) & $\begin{array}{l}\text { Amêndoa de frutos } \\
\text { amarelo claro }\end{array}$ & 29,77 & 1,14 & 9,46 & 48,40 & 4,93 & 10,82 & NA & NA & 199,89 & NA & NA \\
\hline Santana et al. (2011) & Amêndoa & 32,23 & 1,10 & 13,22 & 50,55 & 2,90 & NA & NA & NA & NA & NA & NA \\
\hline \multirow[t]{2}{*}{ Silva et al. (2012) } & Amêndoa & 12,58 & 3,28 & 33,43 & 30,04 & 20,64 & NA & NA & NA & NA & 7,00 & NA \\
\hline & Polpa & 74,94 & 0,56 & 16,03 & 1,53 & 6,94 & NA & NA & NA & NA & $8.706,00$ & NA \\
\hline Santos et al. (2014a) & Farinha da amêndoa & 3,01 & 0,02 & 41,35 & 43,63 & 13,40 & 35,30 & 1,17 & 34,12 & NA & NA & 613,44 \\
\hline Santos et al. (2014b) & Farinha da amêndoa & NA & NA & NA & NA & $\mathrm{NA}$ & 35,08 & 0,93 & 34,11 & 13,38 & NA & NA \\
\hline
\end{tabular}

* $\mathrm{CHO}=$ Carboidratos; $\mathrm{CIN}=$ Cinzas; $\mathrm{CT}=$ Carotenoides Totais; FET = Fenólicos Totais; FII = Fibras Insolúveis; FIS = Fibras Solúveis; FIT = Fibras Totais; LIP = Lipídios; NA = Não Analisado; ND = Não Detectado; PTN = Proteínas; UMI = Umidade; VC = Valor Calórico.

FONTE: Autores.

TABELA 2 - Perfil em ácidos graxos do licuri.

\begin{tabular}{|c|c|c|c|c|c|c|c|c|c|c|c|}
\hline AUTORES & PARTE ANALISADA & $\begin{array}{l}\text { C8:0 } \\
(\%)\end{array}$ & $\begin{array}{c}\text { C10:0 } \\
(\%)\end{array}$ & $\begin{array}{c}\text { C12:0 } \\
(\%)\end{array}$ & $\begin{array}{c}\text { C14:0 } \\
(\%)\end{array}$ & $\begin{array}{c}\text { C16:0 } \\
(\%)\end{array}$ & $\begin{array}{c}\text { C18:0 } \\
(\%)\end{array}$ & $\begin{array}{c}\text { C18:1 } \\
(\%)\end{array}$ & $\begin{array}{c}\text { C18:2 } \\
(\%)\end{array}$ & $\begin{array}{l}\text { SAT. } \\
(\%)\end{array}$ & $\begin{array}{c}\text { INSAT. } \\
(\%)\end{array}$ \\
\hline Miranda \& Silva (2011) & $\begin{array}{l}\text { Óleo da amêndoa de } \\
\text { frutos amarelo claro }\end{array}$ & 12,09 & 6,80 & 42,77 & 14,20 & 6,57 & 2,32 & 11,23 & 2,89 & 84,75 & 14,12 \\
\hline \multirow[t]{2}{*}{ Silva et al. (2012) } & Amêndoa & NA & 9,16 & 44,55 & 19,04 & 10,03 & 3,78 & 13,44 & ND & 86,56 & 13,44 \\
\hline & Polpa & NA & ND & ND & ND & 42,31 & 32,35 & 25,34 & ND & 74,66 & 25,34 \\
\hline
\end{tabular}

* C8:0 = Ácido Caprílico; C10:0 = Ácido Cáprico; C12:0 = Ácido Láurico; C14:0 = Ácido Mirístico; C16:0 = Ácido Palmítico; C18:0 = Ácido Esteárico; C18:1 = Ácido Oleico; C18:2 = Ácido Linoleico; INSAT. = Insaturados; NA = Não Analisado; ND = Não Detectado; SAT. = Saturados.

FONTE: Autores. 


\section{Perspectivas}

Aroucha \& Aroucha (2013) refletem que dentre os principais desafios para a sustentabilidade do extrativismo do licuri, destacam-se a ampliação de mais pesquisas, a capacitação e a disseminação de informações quanto à importância e os potenciais do licuri. Portanto, devido a vasta riqueza de recursos que esta espécie oferece, surgem estudos e perspectivas sobre seu uso. Observa-se, por exemplo, que os seus usos fitoterápicos são comuns, como exemplo, a "água leitosa" do fruto verde é utilizada como colírio para tratamento de inflamações oculares, bem como para o tratamento de micoses e para a cicatrização de feridas, entre outras coisas (Rufino et al., 2008; Aroucha \& Aroucha, 2013).

A lagarta-do-coco (P. nucleorum) é considerada uma das larvas mais populares entre os povos indígenas, sendo coletadas quebrando o licuri para extrair a amêndoa e são encontrados em mais de um terço dos casos. As populações acreditam que essa larva é natural do licuri, ou seja, nasce da própria amêndoa, explicação que justifica seu consumo alimentar e uso medicinal, para tirar manchas de cicatrizes da pele e como cicatrizante (Costa Neto \& Ramos-Elorduy, 2006; Aroucha \& Aroucha, 2013). Já o chá das raízes do licurizeiro é popularmente utilizado para o tratamento de dores na coluna vertebral, como calmante e para diminuir os sintomas do climatério feminino (Rufino et al., 2008; Aroucha \& Aroucha, 2013).

Um estudo desenvolvido por Leal et al. (2013), com o objetivo de determinar o equilíbrio hidrófilolipófilo (EHL) crítico do óleo da amêndoa do licuri e de realizar um ensaio clínico para avaliar os seus efeitos hidratantes, concluíram que o óleo de licuri pode ser considerado um novo adjuvante lipofílico com função hidratante, podendo ser usado em preparações cosméticas, substituindo óleos de uso consagrado.

Por sua vez, Rodrigues et al. (2011) objetivaram investigar a atividade de um extrato aquoso da casca do licuri contra parasitas de Leishmania amazonensis e seus efeitos na infecção por macrófagos e na produção de óxido nítrico. Dentre os resultados, o extrato aquoso não exibiu efeito citotóxico em células de mamíferos (camundongos) e não provocou reações alérgicas in vivo, indicando boas perspectivas para o desenvolvimento de novas drogas de origem fitoterápica para o tratamento da leishmaniose. Os autores relembram, que fármacos candidatos ao tratamento da leishmaniose devem demonstrar uma ação direta e seletiva sobre os parasitas, como a estimulação do sistema imune do hospedeiro, para aumentar a probabilidade de eliminação da infecção. Em conclusão, a toxicidade do extrato aquoso bruto do licuri, rico em procianidina polimérica para L. amazonensis, com ativação macrofágica concomitante e sem reação alérgica in vivo, demonstra o potencial desta palmeira como droga leishmanicida.

Souza et al. (2017), em seu recente trabalho, analisaram a composição química e os efeitos in vitro de óleos essenciais isolados de plantas da Caatinga, dentre elas o licuri, sobre o Trypanosoma cruzi, agente etiológico da doença de Chagas. Os resultados indicam que todos os óleos testados apresentaram efeito inibitório sobre o crescimento e a sobrevivência de todas as formas de $T$. cruzi e moderada citotoxicidade para as células de mamíferos. Com exceção do óleo das amêndoas do licuri, que foi o mais citotóxico para as células de parasitas e de mamíferos. Todos os óleos demonstraram ser 
mais seletivos para o parasita que o benznidazol de referência. Em conclusão, os autores apontam que os óleos essenciais das plantas da Caatinga, especialmente Eugenia brejoensis, como agentes promissores para o desenvolvimento de novas drogas contra a doença de Chagas.

Em outro estudo, Santos et al. (2017) avaliaram o potencial de um óleo volátil extraído de amêndoas do licuri para o controle do Aedes aegypti, vetor de doenças como dengue, febre amarela, chikungunya e zika vírus. A extração do óleo revelou que $98,42 \%$ da composição corresponderam aos ácidos graxos octanóico ou caprílico (40,55\%), decanóico ou cáprico $(17,39 \%)$ e dodecanóico ou láurico $(40,48 \%)$. Demostrando ser capaz de exterminar até $50 \%\left(\right.$ dose letal $\left.50=\mathrm{DL}_{50}\right)$ das larvas dos mosquitos nos testes, com uma dose de 21,07 ppm (parte por milhão), porém não apresentou ação ovicida. Também foram testados os componentes majoritários deste óleo essencial: os ácidos caprílico, cáprico e láurico, os quais mostraram uma atividade larvicida $\left(\mathrm{DL}_{50}\right)$ de 51,78, 24,01 e 19,72 ppm, respectivamente.

Além disso, a atividade de natação de larvas incubadas com o óleo durante 1 e 3 horas foi significativamente $(\mathrm{p}<0,05)$ menor que a das larvas controle $(0,2 \%$ Tween $80, \mathrm{v} / \mathrm{v})$. O óleo de licuri e o ácido caprílico (ambos a 50 ppm) mostraram um efeito dissuasor na oviposição. Portanto, em conclusão, o óleo essencial das amêndoas do licuri foi capaz de promover a morte de larvas de $A$. aegypti e exerceu um efeito dissuasor em fêmeas prenhes. Os resultados indicam que a atividade larvicida é devida à ação dos ácidos cáprico e láurico, enquanto o efeito de dissuasão da oviposição provavelmente está ligado à presença do ácido caprílico.
Existe na literatura uma escassez de estudos sobre o potencial microbiológico do licuri, pouco se sabe sobre seus microrganismos contaminantes ou sobre sua cadeia alimentar de produção. Contudo, Jesus \& Santos (2017) descrevem em seu estudo que o licuri comumente é recolhido no chão, em meio a sujidades e animais. Ressaltam pois, que não se deve colher os frutos no chão e sim na palmeira, como qualquer outro fruto, de forma ambientalmente sustentável, proporcionando um manejo agroecológico e aproveitamento do licuri de forma integral. Bondar (1938) já afirmava que os frutos do licuri devem ser coletados diretamente da árvore quando começam a apresentar queda espontânea, devendo ser despolpados e deixados secar.

Esses licuris colhidos da palmeira, aos quais se denominam licuris selecionados, apresentam maior valor agregado, tendo em vista que é possível seu aproveitamento integral, bem como seu uso em produtos alimentícios (Jesus \& Santos, 2017). Jesus \& Santos (2017), objetivaram criar condições estruturais adequadas para o fortalecimento da cadeia produtiva do licuri, bem como contribuir para a agregação de valor e continuidade de pesquisas. Demostraram resultados significativos, que influenciaram na qualidade dos produtos desenvolvidos a partir do fruto colhido na palmeira, como a mudança no índice de acidez do óleo de licuri, com redução de $14 \%$ para até $0,2 \%$.

Farias et al. (2013), desenvolveram um trabalho com o objetivo de detectar e produzir lipases utilizando como substratos resíduo de licuri por culturas de Aspergillus mantidas em micoteca, selecionar o melhor produtor, verificar as melhores condições de produção da enzima e determinar o efeito e a estabilidade das lipases ao $\mathrm{pH}$ e temperatura. Constataram que em fermentação em estado 
sólido todas as culturas apresentam atividade lipolítica utilizando resíduo de licuri como substrato de baixo custo, sendo que o farelo do licuri demonstrou grande potencial como substrato, possibilitando o bom desenvolvimento quanto à produção de lipases, pois os resultados obtidos mostraram não haver necessidade de utilização de indutores, o que pode levar a uma considerável economia de matérias-primas no processo industrial.

Sabe-se que grãos e sementes são comumente contaminados por diferentes seres patogênicos e não patogênicos (como insetos, bactérias e fungos). Essas contaminações resultam de fatores intrínsecos a esses alimentos, como atividade de água, $\mathrm{pH}$, temperatura e valor nutricional, além das condições inadequadas de armazenamento e processamento (Veras et al., 2016). Um dos principais problemas relacionados à produção desses alimentos é sua contaminação principalmente por fungos produtores de micotoxinas, que são produtos tóxicos derivados do metabolismo de alguns fungos e que possuem alta carcinogenicidade, principalmente em nível hepático. São fungos produtores dessas micotoxinas Aspergillus, Fusarium e Penicillium, que se desenvolvem tanto em alimentos de origem animal como vegetal (Spinelli et al., 2018).

Especialmente a micotoxina, denominada aflatoxina, é produzida por algumas espécies de Aspergillus, principalmente A. flavus e A. parasiticus. Além de ser encontrada com frequência nesses alimentos, além do milho e do leite (Spinelli et al., 2018). De acordo com alguns estudos, as aflatoxinas podem ser um dos componentes mais tóxicos, carcinogênicos, teratogênicos e mutagênicos presente em alimentos (Veras et al., 2016).

\section{Considerações finais}

Espera-se que os resultados decorrentes dessa revisão possam fornecer subsídios científicos que ampliem a interiorização da pesquisa, a capacitação e a disseminação de informações acerca do licuri, contribuindo para otimizar a sua utilização, agregar valor, fortalecer a sua preservação e promover a formação de um Semiárido cada vez mais próspero, inclusivo e sustentável.

\section{Referências}

Antoniassi, R.; Freitas, S. C.; Oliveira S. P.; Vieira, T. M. F. S.; Bizzo, H. R.; Folegatti, M. I. S.; Miranda, P. C. Valor nutricional da amêndoa do licuri (Syagrus coronata) utilizada em preparações culinárias da região do Semi-árido baiano. Embrapa Agroindústria de Alimentos, 2005. Disponível em: https://ainfo.cnptia.embrapa.br/digital/bitstream/ item/127541/1/2005RA-076.pdf.

Aroucha, E. P. T. L.; Aroucha, M. L. Boas Práticas de Manejo para o Extrativismo Sustentável do Licuri. Brasília: Instituto Sociedade, População e Natureza, 2013.

Beltrão, N. E. M.; Oliveira, M. I. P. Oleaginosas Potenciais do Nordeste para a Produção de Biodiesel. Campina Grande: Embrapa, 2007.

Bondar, G. O. Licurizeiro (Cocos coronata Mart.) e suas potencialidades na economia brasileira. Salvador: Instituto Central de Fomento Econômico da Bahia, 1938.

Bondar, G. O. Palmeiras do Brasil. Boletim do Instituto de Botânica, 2, 1-159, 1964.

Carvalho, A. J. A.; Ferreira, M. H. S.; Alves, J. S. O licuri (Syagrus coronata, Arecaceae): lavoura xerófila e agricultura familiar camponesa no Semiárido do centro-norte baiano. Bahia Análise \& Dados, 24(3), 557-569, 2014.

COOPES - Cooperativa de Produção da Região do Piemonte da Diamantina. Festa do licuri 2018. Disponível em: $<$ http:// www.coopes.org.br/>. Acesso em: out. 2018. 
Costa Neto, E. M.; Ramos-Elorduy, J. Los Insectos Comestibles de Brasil: Etnicidad, Diversidad e Importancia En La Alimentación. Boletín Sociedad Entomológica Aragonesa, 1(38), 423-442, 2006. Disponível em: http://sea-entomologia. org/PDF/GeneraInsectorum/GE-0062.pdf.

Crepaldi, I. C.; Almeida-Muradian, L. B.; Rios, M. D. G.; Penteado, M. V. C.; Salatino, A. Composição nutricional do fruto de licuri (Syagrus Coronata (Martius) Beccari). Revista Brasileira de Botânica, 24(2), 155-159, 2001. Disponível em: https://www.scielo.br/pdf/rbb/v24n2/a04v24n2.pdf.

Drumond, M. A. Licuri Syagrus coronata (Mart.) Becc. Petrolina: Embrapa Semi-Árido, 2007.

Farias, C. M. M.; Motta, C. M. S.; Moreira, K. A. Produção e caracterização de lipases de Aspergillus da micoteca urm utilizando resíduo de licuri (Syagrus coronata) (Martius) Beccari como substrato. Recife, Dissertação (Mestrado em Biologia de Fungos) - UFPE, 2013.

Feltrin, K. L.; Brennan, I. M.; Rades, T.; Horowitz, M. Feinle-Bisset, C. Acute oral administration of lauric acid reduces energy intake in healthy males. e-SPEN Journal, 9(2), 2014.

Folegatti, M. I. S.; Ferreira, G. F.; Miranda, P. C.; Freitas, S. C.; Antoniassi, R.; Bizzo, H. R. Desenvolvimento de biscoitos mistos de fécula de mandioca e licuri: otimização da formulação e análise da composição. Embrapa Meio Ambiente, 2006. Disponível em: https://ainfo.cnptia.embrapa.br/digital/ bitstream/item/135067/1/2006RA-080.pdf.

Jesus, D. S.; Santos, C. R. S. Programa colhedores de licuri: uma proposta de metodologia para inovação e inclusão social. ciKi: Congresso Internacional de Conhecimento e Inovação, 1(1), 1-6, 2017.

Leal, B. L.; Sousa, G. D.; Seixas, K. B.; Souza, P. H. N.; Santana, D. P. Determination of the critical hydrophile-lipophile balance of licuri oil from Syagrus coronata: application for topical emulsions and evaluation of its hydrating function. Brazilian Journal Of Pharmaceutical Sciences, 49(1), 167-173, 2013. Disponível em: https://www.scielo.br/pdf/ bjps/v49n1/a18v49n1.pdf.

Lima, D. M.; Tenório, S.; Gomes, K. Dieta por Anodorhynchus leari Bonaparte, 1856 (Aves: Psittacidae) em palmeira de licuri na caatinga baiana. Atualidades Ornitológicas, 2014. Disponível em: http://www.ao.com.br/download/
AO178_50.pdf.

Maia, J. M.; Sousa, V. F. O.; Lira, E. H. A.; Lucena, A. M. A. Motivações socioeconômicas para a conservação e exploração sustentável do bioma caatinga. Desenvolvimento e Meio Ambiente, 41, 295-310, 2017. Disponível em: https://revistas. ufpr.br/made/article/view/49254/33415.

Miranda, K. E. S.; Silva, S. M. Qualidade e atividade antioxidante de fruto e seu óleo de genótipos do licurizeiro (Syagrus coronata). João Pessoa, Tese (Doutorado em Ciência e Tecnologia de Alimentos) - UFPB, 2011.

Mohammed, N.; Onodera, R.; Itabashi, H.; Lila, Z. A. Effects of ionophores, vitamin B6 and distiller's grains on in vitro tryptophan biosynthesis from indolepyruvic acid, and production of other related compounds by ruminal bacteria and protozoa. Animal Feed Science and Technology, 116, 301-311, 2004. doi: 10.1016/j.anifeedsci.2004.07.017.

Oliveira, A. M. R. S.; Carvalho, R. F. Caracterização da fibra do licuri (Syagrus coronata (Martius) Beccari) para aplicações na construção civil. Salvador, Dissertação (Mestrado em Engenharia Ambiental Urbana) - UFBA, 2010.

Oliveira, M. B. F.; Meneghetti, S. M. P.; Soletti, J. I. Estudo integrado da espécie paleira ouricuri (Syagrus coronata (Martius) Beccari) para geração de energia. Maceió, Dissertação (Mestrado em Engenharia Química) - UFAL, 2013.

Oliveira, U. R.; Espirito Santo, F. S. E.; Alvarez, I. A. Comunidade epifítica de Syagrus coronata (Mart.) Becc. (Arecaceae) em áreas de pastagens na Caatinga, Bahia. Revista Caatinga, 28(2), 84-91, 2015. Disponível em: https://periodicos.ufersa. edu.br/index.php/caatinga/article/view/4099/pdf 249.

Ramos-Elorduy, J.; Costa Neto, E. M.; Santos, J. F.; Moreno, J. M. P.; Landero-Torres, I.; Campos, S. C. A.; Pérez, A. G. Estudio comparativo del valor nutritivo de varios Coleoptera comestibles de México y Pachymerus nucleorum (Fabricius, 1792) (Bruchidae) de Brasil. Interciencia, 31(7), 512-516, 2006.

Rocha, K. M. R.; Chaves, L. F. C.; Passos, M. A. A.; Machado, I. C. S. Biologia reprodutiva da palmeira licuri (Syagrus coronata (Mart.) Becc.) (Arecaceae) na ecorregião do Raso da Catarina, Bahia. Recife, Dissertação (Mestrado em Ciências Florestais) - UFRPE, 2009. 
Rodrigues, I. A.; Alviano, D. S.; Gomes, M. T.; Silva, D. O.; Antoniassi, R.; Silva, A. J.; Bizzo, H. R.; Alviano, C. S.; Vermelho, A. B.; Rosa, M. S. S. In vitro anti-Leishmania amazonensis activity of the polymeric procyanidin-rich aqueous extract from Syagrus coronata. Journal Of Medicinal Plants Research, 5(16), 3781-3790, 2011. Disponível em: https:// ainfo.cnptia.embrapa.br/digital/bitstream/item/43040/1/2011052.pdf.

Rufino, M. U. L.; Costa, J. T. M.; Silva, V. A.; Andrade, L. H. C. Conhecimento e uso do ouricuri (Syagrus coronata) e do babaçu (Orbignya phalerata) em Buíque, PE, Brasil. Acta Botânica Brasílica, 22(4), 1141-1149, 2008. Disponível em: https://www.scielo.br/pdf/abb/v22n4/a25v22n4.pdf.

Santana, J. S.; Silva, L. S.; Sales, I. C.; Piras, P. R. F. Caracterização físico-química de caju-passa, licuri e seus produtos derivados produzidos no interior baiano. SEMIC: Seminário de Iniciação Científica, 579-582, 2011. Disponível em: http://www2.uefs.br/semic/upload/2011/2011XV-028JAM465-310.pdf.

Santos, J. A. R.; Athayde Filho, P.; Wanderley, P. A. Avaliação das propriedades físico-químicas, fluidodinâmicas e oxidativas do biodisel de licuri (Syagrus coronata) e das blendas (licuri/soja). João Pessoa, Dissertação (Mestrado em Química) - UFPB, 2011;

Santos, L. M. M.; Nascimento, J. S.; Santos, M. A. G.; Marriel, N. B.; Bezerra-Silva, P. C.; Rocha, S. K. L.; Silva, A. G.; Correia, M. T. S.; Paiva, P. M. G.; Martins, G. F. Fatty acid-rich volatile oil from Syagrus coronata seeds has larvicidal and oviposition-deterrent activities against Aedes aegypti. Physiological And Molecular Plant Pathology, 100, 35-40, 2017. doi: 10.1016/j.pmpp.2017.05.008

Santos, M. H. O.; Simionato, J. I.; Gualberto, S. A. Aproveitamento Tecnológico de Resíduo do Processamento do Licuri (Syagrus coronata). Itapetinga, Dissertação (Mestrado em Engenharia de Alimentos) - UESB, 2014a.

Santos, M. H. O.; Simionato, J. I.; Gualberto, S. A.; Santana, R. F.; Silva, M. H. S. Quantificação de compostos bioativos da farinha de licuri: fenólicos totais e fibras. Agrarian Academy, 1(02), 52, 2014b. Disponível em: http://www.conhecer. org.br/Agrarian $\% 20$ Academy $/ 2014 \mathrm{~b} /$ quantificacao $\% 20$ de $\% 20$ compostos.pdf.
Silva, M. L. C.; Costa, R. S.; Santana, A. S.; Koblitz, M. G. B. Compostos fenólicos, carotenóides e atividade antioxidante em produtos vegetais. Semina: Ciências Agrárias, 31(3), 669-682, 2010. Disponível em: http://www.uel.br/revistas/ uel/index.php/semagrarias/article/viewFile/6510/5926.

Silva, R. B.; Oliveira, A. F. M.; Andrade, L. H. C. Potencial nutricional de seis espécies de Arecaceae ocorrentes em Pernambuco, Nordeste do Brasil. Recife, Dissertação (Mestrado em Biologia Vegetal) - UFPE, 2012.

Silva, T. S.; Henrique, D. C.; Meili, L.; Soletti, J. I.; Carvalho, S. H. V. Utilização da fibra do Ouricuri (Syagrus coronata) na remoção do corante azul de metileno: variáveis de processo e isoterma de adsorção. ENEMP: Congresso Brasileiro de Sistemas Particulados, 2015. Disponível em: http://pdf. blucher.com.br.s3-sa-east-1.amazonaws.com/chemicalengineeringproceedings/enemp2015/PS-689.pdf.

Slow Food. Comida com gosto de licuri: receitas. COOPES: Cooperativa de Produção da Região do Piemonte da Diamantina, 2015.

SBC - Sociedade Brasileira de Cardiologia. Atualização da Diretriz Brasileira de Dislipidemias e Prevenção da Aterosclerose - 2017. Arquivos Brasileiros de Cardiologia. 109(1), 2017.

Souza, L. I. O.; Bezzera-Silva, P. C.; Navarro, D. M. A. F.; Silva, A. G.; Correia, M. T. S.; Silva, M. V.; Figueiredo, R. C. B. Q. The chemical composition and trypanocidal activity of volatile oils from Brazilian Caatinga plants. Biomedicine \& Pharmacotherapy, 96(1), 1055-1064, 2017. doi: 10.1016/j. biopha.2017.11.121

Spinelli, L.; Longoni, L.; Silveira, A. B. Análise microbiológica de amostras de amendoim provenientes do mercado público de Porto Alegre/RS. Revista de Ciências Ambientais, 12(2), 39-49, 2018. Disponível em: doi: 10.18316/rca.v12i2.4365

Veras, L. N.; Cavalcante, E. O.; Barbosa, J. M.; Alves, T. P.; Alves, J. M. S.; Pantoja, L. D. M. Análise micológica de sementes de amendoim (Arachis hypogaea) caseiras e industrializadas comercializadas em Fortaleza, Ceará. $\mathrm{Nu}$ trivisa: Revista de Nutrição e Vigilância em Saúde, 2(3), 134-140, 2016. Disponível: http://www.revistanutrivisa.com. br/wp-content/uploads/2016/03/nutrivisa-vol-2-num-3-g.pdf. 